\title{
Seismic Response of Plan-Asymmetric Structures with Diaphragm Flexibility
}

\author{
Hamed Eivani $\mathbb{D},{ }^{1}$ Abdolreza S. Moghadam $\left(\mathbb{D},{ }^{2}\right.$ Armin Aziminejad, ${ }^{1}$ and Masoud Nekooei ${ }^{1}$ \\ ${ }^{1}$ Department of Civil Engineering, Science and Research Branch, Islamic Azad University, Tehran, Iran \\ ${ }^{2}$ International Institute of Earthquake Engineering and Seismology (IIEES), Tehran, Iran \\ Correspondence should be addressed to Abdolreza S. Moghadam; moghadam@iiees.ac.ir
}

Received 28 June 2017; Revised 30 October 2017; Accepted 3 December 2017; Published 15 January 2018

Academic Editor: Naveed Ahmad

Copyright (c) 2018 Hamed Eivani et al. This is an open access article distributed under the Creative Commons Attribution License, which permits unrestricted use, distribution, and reproduction in any medium, provided the original work is properly cited.

\begin{abstract}
The seismic behavior of asymmetric structures with a flexible diaphragm was studied by conducting inelastic dynamic time-history analyses. Asymmetric structures with different configurations of mass, stiffness, and strength centers, in combination with a wide range of diaphragm flexibility, were evaluated. The behavior of structures was studied by considering three aspects: (1) effect of structural asymmetry on diaphragms deformation; (2) effect of diaphragm flexibility on demands of the lateral load-resisting elements; (3) optimum configuration of mass, stiffness, and strength centers to limit important engineering demand parameters in asymmetric structures with a flexible diaphragm. The results showed that the shear-dominant deformation of diaphragms is sensitive to both structure asymmetry specifications and the degree of diaphragm flexibility; therefore, it can be used for the qualitative classification of the seismic behavior of structures. Also, the center of strength in structures with flexible diaphragm is more important relative to the stiffness center and has a significant effect on engineering demands at all levels of diaphragm flexibility. Moreover, it was found that a suitable configuration of centers in torsionally stiff structures depends on the degree of diaphragm flexibility, in addition to the intensity of earthquakes (structure yield level) and selected engineering demand parameter.
\end{abstract}

\section{Introduction}

In some structures, the assumption of a fully rigid seismic diaphragm is far from reality and can lead to a significant difference in the actual responses of structure and the results of analysis [1-3]. The type of floor system is an important factor in the degree of diaphragm flexibility. Many types of reinforced concrete floors such as prestressed beam and block [4], RC waffle slabs [5], ribbed RC slabs [6], and the traditional beam and block floor systems [7] can be considered as flexible diaphragms under certain conditions. Based on previous studies, diaphragm flexibility depends not only on the floor type, but also on other parameters such as the diaphragm aspect ratio and ratio of diaphragm stiffness to adjoining lateral elements stiffness [6].

Previous studies suggest that plan-asymmetric structures have more potential for diaphragm flexibility $[2,8,9]$. In planasymmetric structures, the degree of diaphragm flexibility and distribution of structure stiffness and strength are key parameters that affect the distribution of forces between the lateral load-resisting elements (LLREs) simultaneously. On the other hand, LLREs forces and deformations affect the response of diaphragms and their components. Therefore, there is a close relationship between diaphragm flexibility and structural asymmetry. Most previous studies have examined extreme cases of this relationship. For example, when the diaphragm is quite rigid, the distribution of stiffness and strength in the structure plan has the greatest effects on the seismic response of plan-asymmetric structures. However, for absolutely flexible diaphragms, the distribution of force between the LLREs is only based on their tributary area.

While past earthquakes observations [10, 11] clearly showed that the diaphragm of many structures has a semiflexible performance, the behavior of plan-asymmetric structures with a semiflexible diaphragm has received less attention in previous studies and some issues remain unresolved. These issues include (1) the effect of stiffness and strength eccentricity parameters on the deformation demands of 
flexible diaphragms, (2) the effect of diaphragm flexibility on the response of LLREs of asymmetric structures, especially in the field of nonlinear behavior, and (3) proper configuration of centers with the aim of limiting engineering demand parameters (EDPs) in plan-asymmetric structures with a flexible diaphragm.

In the current study, a parametric study was conducted to address these issues. Simple numerical models were used to determine the general characteristics of the seismic response of plan-asymmetric structures with flexible diaphragms. A wide range of diaphragm flexibility was considered for eight single-story structures with different and realistic configurations of stiffness, strength, and mass centers. Models were exposed to a suite of unidirectional earthquake records with two different intensities (DBE and MCE). The mean maximum displacements and ductility demands of LLREs and deformation components of diaphragms were evaluated using an inelastic dynamic time-history analyses. In order to compare the results, elastic analysis of the structures was performed.

\section{A Review of Previous Studies on Flexibility of Seismic Diaphragm}

Several studies have been conducted on the effects of diaphragm flexibility on structures with different dimensions, lateral load-resisting systems, stories height, and numbers. The results indicated that diaphragm flexibility is more important in structures with stiffer LLREs such as shear walls $[2,12]$, lower story height $[12]$, less number of stories $[1,12-$ $14]$, less number of structure spans $[1,13]$, and larger aspect ratios [12-14].

Diaphragm flexibility affects the dynamic characteristics of structures. For example, it increases the natural vibrational periods of structures $[1,3]$, and also the participation of higher modes in structural response $[14,15]$. An increase in the period, depending on the natural period of the initial structure with rigid diaphragm and the soil type, can cause an increase in the spectral acceleration (ascending branch), decrease in spectral acceleration (descending branch), or no change in the spectral acceleration (fixed branch) in structures with diaphragm flexibility [6]. Also, diaphragm flexibility can lead to the modification of mode shapes and cause a phenomenon called "mode shift" in which some modes of the structure with rigid diaphragm appear in higher modes of similar structures with a flexible diaphragm [13].

Diaphragm flexibility causes changes in the distribution of forces in the LLREs. For example, while in symmetric structures with rigid diaphragm all elements experience the same deformation and accordingly, the stiffer elements absorb more lateral forces in those with absolutely flexible diaphragms; as previously mentioned, the distribution of force between the LLREs is only based on their tributary area [3].

One of the other important issues addressed in flexible diaphragm studies is the local failures of the diaphragms connections with LLREs, especially in the unreinforced masonry structures (URM) that can lead to out of plane failures of walls $[10,11,16,17]$.

Fewer studies have addressed diaphragm flexibility in plan-asymmetric structures, in comparison with symmetric structures. Studies have shown that, with increase in flexibility, the effects of stiffness eccentricity and consequently the torsional response of the structures reduce significantly [8]. This performance has been introduced as one of the noticeable advantages of diaphragm flexibility [6].

De-La-Colina [8] examined the seismic response of onespan, single-story plan-asymmetric structures with a flexible diaphragm. The investigated structures had stiffness eccentricity and it was assumed that the strength of elements is independent of their stiffness, and, consequently, the strength of structure was distributed among the LLREs according to their stiffness. It was concluded that, by increasing the initial natural period of the structure and the level of elements yield (increase in force reduction factor), the flexibility effects are reduced.

In a parametric study, Kim and White [18] evaluated the structural behavior of one-story reinforcement masonry buildings with timber diaphragm in the inelastic range. They found that the maximum wall displacement occurs when the diaphragm has a semirigid behavior.

Nakamura et al. [19] investigated the impacts of diaphragm flexibility on masonry structures. In asymmetric structures, it was assumed that the strength center coincided with the stiffness center. They concluded that the diaphragm flexibility, depending on the degree of eccentricity, can have different effects on the responses of LLREs. Their study also showed that the stiffness and strength of orthogonal side elements, except in structures with very stiff diaphragms, do not have much impact on responses.

While the experiences of past earthquakes clearly show that the diaphragms of many structures have a semiflexible behavior, the likely change in response of plan-asymmetric structures for different levels of diaphragm flexibility is unknown and less addressed in previous studies. Therefore, the identification of asymmetric structures behavior with a flexible diaphragm is one of the main objectives of the present study.

\section{Configuration of Stiffness and Strength Centers in Plan-Asymmetric Buildings}

In seismic design, the lateral elements nonlinear momentcurvature can be considered satisfactory as an ideal bilinear relationship [20]. Also, the researches conducted on the concrete columns and shear walls $[21,22]$ showed that yield displacement of LLREs (D-type elements [23]) is only dependent on the material properties and geometric dimensions of elements and is independent of its axial force and strength (reinforcement ratio). Based on these assumptions, the yield displacement for a cantilever shear wall with different conditions of loading $\left(\Delta_{y}\right)$ can be calculated from [24]

$$
\Delta_{y}=\frac{C \varepsilon_{y} h^{2}}{l_{w}},
$$




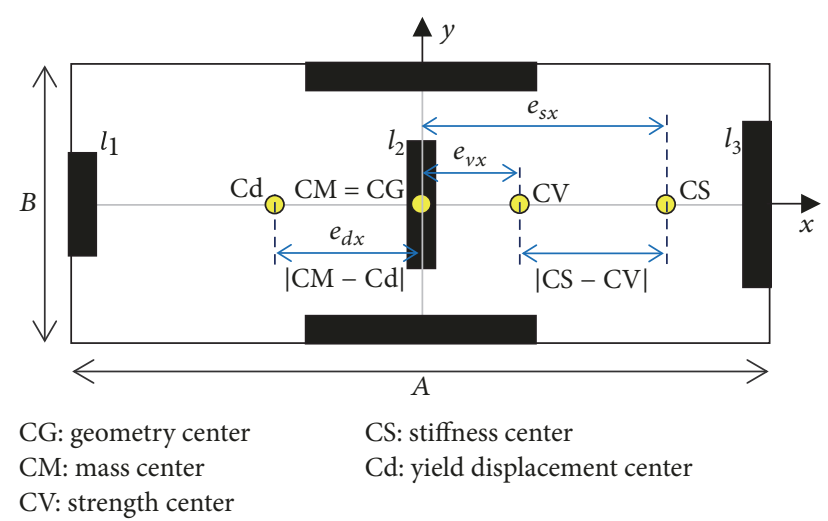

FIgURE 1: Centers of structural model and their eccentricities.

where $l_{w}$ and $h$ are, respectively, the length and height of the shear wall, $\varepsilon_{y}$ is the yield strain of longitudinal reinforcements, and $C$ is a coefficient related to the shape of lateral force distribution and element section. For example, for a cantilever shear wall with lateral load acting on the top of the wall (as in a single-story building), the value of $C$ is equal to 0.66 .

Unlike the traditional assumption, element stiffness depends on its nominal strength and is not a constant property. Therefore, the stiffness of the lateral load-resisting element $\left(K_{i}\right)$ can be calculated according to (2) using the nominal base shear strength of the wall and its yield displacement (see (1)) [24]:

$$
K_{i}=\frac{V_{n i}}{\Delta_{y i}}
$$

where $V_{n i}$ and $\Delta_{y i}$ are the nominal strength and yield displacement of the element, respectively. $\Delta_{y i}$ for a cantilever shear wall is given by (1).

Therefore, in buildings consisting of D-type elements, the location of the stiffness center is a function of their strength and yield displacement. In a study, Tso and Myslimaj [25] showed that even in the case of using different methods to assign strength to LLREs, the distance between the centers of strength and stiffness will be almost equal to the distance between the centers of mass and yield displacement.

The models considered in this study had three shear walls in the direction of the applied seismic load (unidirectional excitations applied in the $y$ direction) (Figure 1).

In this figure, $\mathrm{CM}, \mathrm{CS}, \mathrm{CV}$, and $\mathrm{Cd}$ are, respectively, mass, stiffness, strength, and yield displacement centers of structures. The lengths of walls from left to right are $l_{1}, l_{2}$, and $l_{3}$ and their distances from the geometric center of the diaphragm are equal to $-A / 2,0$ and $A / 2$, respectively. As shown in Figure 1, the center of mass (CM) coincides with the geometric centroid (CG). Uniaxial stiffness eccentricity $\left(e_{s x}\right.$, defined as the distance between CM and the center of stiffness, CR) and strength eccentricity $\left(e_{v x}\right.$, defined as the distance between the CM and the center of strength, CV) are introduced by change in edge walls strength and length. Stiffness, strength, and yield displacement of the $i$ th wall oriented in the $y$ direction are defined by $K_{y i}, V_{y i}$, and $\Delta_{y i}$, respectively, and the wall located at a distance $x_{i}$ from the CM. The configuration of the analytical models is defined by the following parameters:

(a) The yield displacement eccentricity is expressed as normalized to the dimension of the diaphragm perpendicular to the direction of excitation $\left(\varepsilon_{d x}\right)$.

$$
\varepsilon_{d x}=\frac{e_{d x}}{A}=\frac{1}{A} \frac{\sum_{i=1}^{3} \Delta_{y i} x_{i}}{\sum_{i=1}^{3} \Delta_{y i}}=\frac{\left(l_{2} l_{1}-l_{3} l_{2}\right)}{2\left(l_{2} l_{3}+l_{1} l_{3}+l_{1} l_{2}\right)} .
$$

It is notable that since in the model shown in Figure 1, the height, material properties, and coefficient $C$ of all LLREs are considered the same, therefore, their yield displacement is inversely proportional to the length of the elements $\left(\Delta_{y i} \propto\right.$ $\left.1 / l_{i}\right)$.

(b) The stiffness eccentricity is expressed as normalized to the dimension of the diaphragm perpendicular to the direction of excitation $\left(\varepsilon_{s x}\right)$.

$$
\varepsilon_{s x}=\frac{e_{s x}}{A}=\frac{1}{A} \frac{\sum_{i=1}^{3} k_{i} x_{i}}{\sum_{i=1}^{3} k_{i}}=\frac{\left(V_{3} l_{3}-V_{1} l_{1}\right)}{2\left(V_{1} l_{1}+V_{2} l_{2}+V_{3} l_{3}\right)} .
$$

(c) The strength eccentricity is expressed as normalized to the dimension of the diaphragm perpendicular to the direction of excitation $\left(\varepsilon_{v x}\right)$.

$$
\varepsilon_{v x}=\frac{e_{v x}}{A}=\frac{1}{A} \frac{\sum_{i=1}^{3} V_{i} x_{i}}{\sum_{i=1}^{3} V_{i}}=\frac{\left(V_{3}-V_{1}\right)}{2\left(V_{1}+V_{2}+V_{3}\right)} .
$$

Aziminejad and Moghadam [26] showed that, in this model, for eccentricities of yield displacement and strength in the range of -15 to $15 \%$, the distance between centers of strength and stiffness can be assumed to be equal to yield displacement eccentricity with an acceptable approximation.

Although these eccentricities are typically used to explain the asymmetry in structures with rigid diaphragm, in some researches conducted on asymmetric structures with flexible diaphragm, the same indices in similar structures to rigid diaphragm were used as convenient definitions $[8,19]$. Accordingly, in this study, the eccentricities in structures with flexible diaphragms mean the same values in similar structures with rigid diaphragms.

\section{Studied Models}

In order to study the combined effects of asymmetry and flexibility in structures, different configurations of the mass, stiffness, and strength centers were considered in the evaluated models. A one-story ideal model with a rectangular plan (diaphragm) and dimensions of $30 \mathrm{~m} \times 12 \mathrm{~m}$ and shear wall system was considered. The height of the model was equal to $3.2 \mathrm{~m}$ and the floor masses $\left(850 \mathrm{~kg} / \mathrm{m}^{2}\right)$ were distributed across the diaphragm uniformly. The base model has two shear walls in the $x$ direction and three shear walls in the $y$ direction, respectively. Building asymmetry was only relative to the $y$-axis (Figure 2). 
TABLE 1: Strength and stiffness of LLREs in analytical models.

\begin{tabular}{lcccccccccc}
\hline \multirow{2}{*}{ Model } & \multirow{2}{*}{ Description } & \multicolumn{3}{c}{ Length (cm) } & \multicolumn{3}{c}{ Strength (Ton) } & \multicolumn{4}{c}{ Stiffness (ton/cm) } \\
& & Wall 1 & Wall 2 & Wall 3 & Wall 1 & Wall 2 & Wall 3 & Wall 1 & Wall 2 & Wall 3 \\
\hline 1 & Symmetric & 200 & 200 & 200 & 17.85 & 17.85 & 17.85 & 36.99 & 36.99 & 36.99 \\
2 & Stiffness symmetric & 260 & 200 & 140 & 12.50 & 17.85 & 23.21 & 33.66 & 36.99 & 33.66 \\
3 & Balance (0.75 CV-CS) & 260 & 200 & 140 & 13.83 & 17.85 & 21.87 & 37.26 & 36.99 & 31.71 \\
4 & Balance (0.5 CV-CS) & 260 & 200 & 140 & 15.17 & 17.85 & 20.53 & 40.87 & 36.99 & 29.77 \\
5 & Balance (0.25 CV-CS) & 260 & 200 & 140 & 16.51 & 17.85 & 19.19 & 44.47 & 36.99 & 27.83 \\
6 & Strength symmetric & 260 & 200 & 140 & 17.85 & 17.85 & 17.85 & 48.08 & 36.99 & 25.89 \\
7 & De Stefano (0.25 CM-CS) & 260 & 200 & 140 & 19.63 & 17.85 & 16.07 & 52.88 & 36.99 & 23.30 \\
8 & De Stefano (0.5 CM-CS) & 260 & 200 & 140 & 23.21 & 17.85 & 12.50 & 62.51 & 36.99 & 18.12 \\
\hline
\end{tabular}

TABLE 2: Eccentricity of asymmetric buildings.

\begin{tabular}{|c|c|c|c|c|c|}
\hline \multirow{2}{*}{ Model } & \multirow{2}{*}{ Description } & \multicolumn{3}{|c|}{ Eccentricity (\%) } & \multirow{2}{*}{$e_{v} / e_{d}$} \\
\hline & & Yield displacement & Strength & Stiffness & \\
\hline 1 & Symmetric & 0 & 0 & 0 & 0 \\
\hline 2 & Stiffness symmetric & 10 & 10 & 0 & 1 \\
\hline 3 & Balance (0.75 CV-CS) & 10 & 7.5 & -2.5 & 0.75 \\
\hline 4 & Balance (0.5 CV-CS) & 10 & 5.0 & -5 & 0.5 \\
\hline 5 & Balance (0.25 CV-CS) & 10 & 2.5 & -7.5 & 0.25 \\
\hline 6 & Strength symmetric & 10 & 0 & -10 & 0 \\
\hline 7 & De Stefano (0.25 CM-CS) & 10 & -3.33 & -13.33 & -0.33 \\
\hline 8 & De Stefano (0.5 CM-CS) & 10 & -10 & -20 & -1 \\
\hline
\end{tabular}

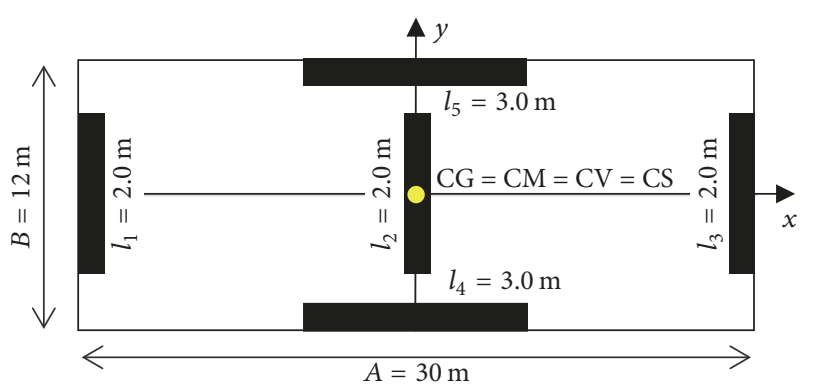

FIGURE 2: Plan view of the base symmetric model.

It was assumed that gravity loads are transferred by a simple frame system. The analysis and design of LLREs were carried out based on the characteristics of the base symmetric model and assuming full rigidity of the seismic diaphragm. Gravity design loads of structures were determined based on the sixth part of the National Building Code of Iran [27]. Seismic design loads were calculated based on seismic provisions of Standard 2800 of Iran [28]. The structure force reduction factor was considered to be equal to 5.0 based on the Standard 2800. The total base shear of the symmetric structure was calculated as 53.55 tons $(535.5 \mathrm{KN})$. To create asymmetric models, the length of the left and right walls of the structure changed in such a way that the yield displacement eccentricity of the structure was equal to $10 \%$ of the plan length. Therefore, the wall lengths were similar in all the asymmetric models. The lengths of left, central, and right walls were considered as 260,200 , and $140 \mathrm{~cm}$, respectively
TABLE 3: Natural period and torsional to lateral frequency ratios $(\Omega)$ of models with rigid diaphragm assumption.

\begin{tabular}{lccccc}
\hline \multicolumn{1}{l}{ Model Mode $x(\mathrm{sec})$} & Mode $y(\mathrm{sec})$ & Mode $\theta(\mathrm{sec})$ & $\Omega_{x}$ & $\Omega_{y}$ \\
\hline 1 & 0.381 & 0.330 & 0.231 & 1.649 & 1.429 \\
2 & 0.381 & 0.330 & 0.231 & 1.649 & 1.429 \\
3 & 0.381 & 0.339 & 0.238 & 1.601 & 1.424 \\
4 & 0.381 & 0.339 & 0.234 & 1.628 & 1.449 \\
5 & 0.381 & 0.342 & 0.230 & 1.656 & 1.487 \\
6 & 0.381 & 0.346 & 0.226 & 1.685 & 1.531 \\
7 & 0.381 & 0.354 & 0.221 & 1.723 & 1.602 \\
8 & 0.381 & 0.376 & 0.209 & 1.823 & 1.799 \\
\hline
\end{tabular}

(Table 1). The length of the two orthogonal side walls (in $x$ direction) was considered the same in all models and equal to $300 \mathrm{~cm}$. The width of all the walls was considered the same and equal to $30 \mathrm{~cm}$. To create different degrees of the strength eccentricity, the strength of the left wall increased, while the strength of the right wall decreased, such that the overall strength of the structure was assumed to be fixed and the same strength of the base symmetric model. Revealing the initial yield displacement of any structural elements from (1) and their initial strength (Table 1), the initial stiffness of elements can be determined using (2).

Also, the eccentricities of structure models can be calculated from (3) to (5) (Table 2). Natural periods and also the torsional to lateral frequency ratio of analytical models assuming the full rigidity of the diaphragm are presented in Table 3. 


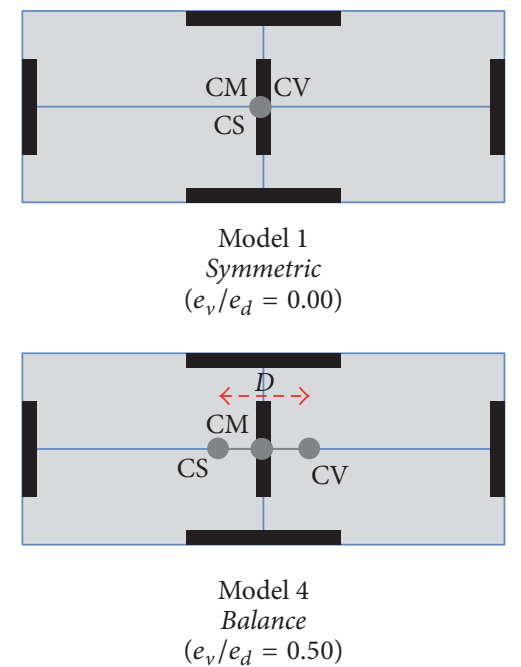

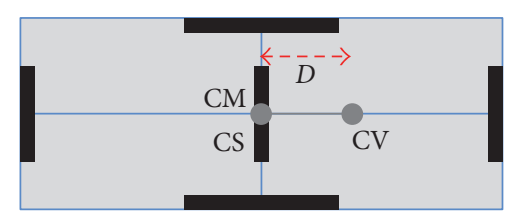

Model 2

Stiffness symmetric

$\left(e_{v} / e_{d}=1.00\right)$

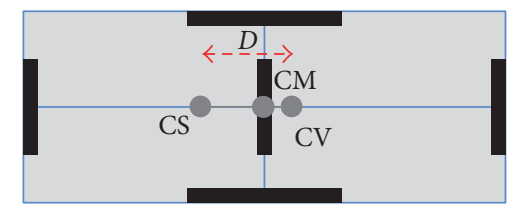

Model 5

Balance

$\left(e_{v} / e_{d}=0.25\right)$

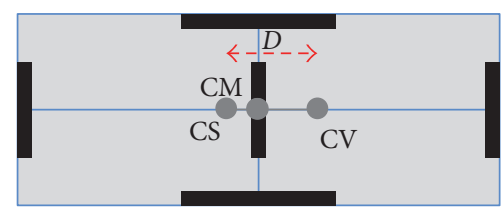

Model 3

Balance

$\left(e_{v} / e_{d}=0.75\right)$

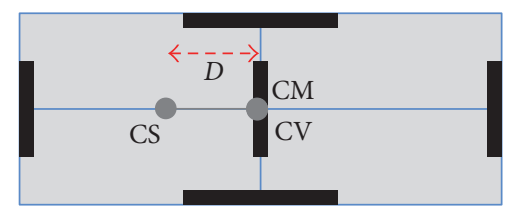

Model 6

Strength symmetric

$\left(e_{v} / e_{d}=0.00\right)$
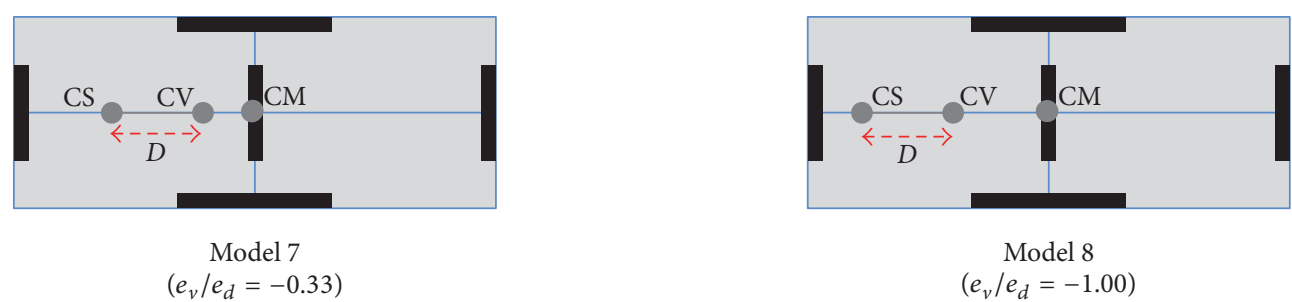

Model 8

$\left(e_{v} / e_{d}=-1.00\right)$

FIGURE 3: Schematic view of centers configuration in models (distance is not in scale).

Given that the torsional to lateral frequency ratio is larger than one in all the models, all the primary models are considered torsionally stiff and their responses are predominantly in transitional mode. The mentioned models are similar to models used in previous studies and as a representative of a wide range of asymmetric buildings [29].

The configuration of centers of the symmetric model and seven plan-asymmetric models are depicted in Figure 3.

These models have been briefly described as follows. Model 1 is the base symmetric model with a regular geometric shape and uniform distribution of mass, stiffness, and strength in its plan. In model 2, the stiffness center coincided with the center of mass. Models 3 to 5 which were presented by Myslimaj and Tso [30, 31] are called "balance configuration" models. The center of the mass is located between the stiffness and strength centers in these three models. In model 3, the distance between the center of mass and the center of strength is about 0.75 of the distance between the stiffness center and the strength center. The distance between the center of mass and the center of strength in models 4 and 5 is, respectively, 0.5 and 0.25 of the distance between the center of stiffness and the center of strength. Model 6 is a model with uniform strength distribution and stiffness eccentricity. Models 7 and 8 are known as "optimum configuration" models according to the study of De Stefano et al. [32]. In model 7, the distance between the mass center and strength center is 0.25 of the distance between the mass center and the stiffness center, while in model 8 , the strength center is between the mass and stiffness centers and in an equal distance from each of them.
After determining the configuration of centers in eight structures with rigid diaphragms, different degrees of flexibility were considered for the diaphragm and the responses of the structures were determined using finite element modeling and inelastic dynamic time-history analyses.

Although the most powerful method of identifying all failure mechanisms in structures is nonlinear modeling by considering the details of diaphragms and their connections, this method is complicated and very time consuming. With the increasing complexity of the model and lack of detailed information, sources of error in the model are likely to increase. Since the main objective of this research was to investigate the overall characteristics of the dynamic responses of asymmetric structures with flexible diaphragm, and the relatively simple models are able to estimate the overall response of the structure, the simplifying assumptions were considered in the ideal model. Some of the most important assumptions and details considered in the design and analysis of selected models include the following:

(1) Based on the principles of many seismic design codes $[28,33]$, seismic diaphragms must be designed in such a way that they behave in the elastic range; in this study, the elastic behavior was proposed for the diaphragms. As pointed out by Tena-Colunga et al. [6], the stiffness properties of some concrete diaphragms such as two-way concrete slabs, ribbed RC slabs, and RC waffle flat slabs in two main directions are the same and therefore an isotropic material modeling can be used to model their stiffness properties in the elastic range. In modeling, the overall diaphragm stiffness was considered 




FIGURE 4: Finite element model of structures and main displacement recorders.

and the flexural stiffness of the diaphragm beams was not considered explicitly.

Based on given descriptions for diaphragms modeling, 384 shell elements with isotropic elastic behavior were used. The diaphragm modeling was performed in OpenSees [34] using the Elastic Membrane Plate Section commands for the diaphragm cross section and the ShellMITC4 command for the diaphragm element type. A complete description of the material, element type models, and their parameters is given in the OpenSees Manual [35]. The ideal analytical model and main recorders of wall displacements and structure diaphragms are shown in Figure 4.

Also, the mesh sensitivity analysis was performed and approved. In another simplification, it was assumed that the diaphragm is completely and continuously connected to the LLREs. Also, the connection of diaphragms to the walls in all seismic levels was considered perfect and without any imperfections.

Since the shear walls of the structure modeled using spring models are connected to the diaphragm at a point, to make the results more realistic and prevent strain concentration at the connection point, especially in very flexible diaphragms, as depicted in Figure 4, the axial stiffness of the main beams was added to the analytical model using one-dimensional truss elements. The axial stiffness of these elements was calculated based on the initial design (under gravity and seismic loads).
(2) In each model, the material properties of the two structure diaphragms were considered identical, and the fundamental natural period of the individual diaphragm with fixed ends $\left(T_{d}\right)$ was used to express the degree of flexibility.

Different values of the diaphragms period considered in this study are presented in Table 4. Diaphragm thickness was considered a realistic value $(0.15 \mathrm{~m})$. Also as previously mentioned, structure plan dimensions were considered constant for all analytical models $(12 \mathrm{~m} \times 30 \mathrm{~m})$. The flexible diaphragm modulus of elasticity $\left(E_{d}\right)$ was calculated using error and trial method so that the structure diaphragm period converges to the target values in Table 4.

In order to better understand this parameter, the corresponding amounts of diaphragm flexibility ratio $\left(\gamma_{s}\right)$ in the symmetric structure are given in the table in accordance with the common definition of diaphragm flexibility ratio in seismic codes [33]. Diaphragm flexibility ratio $\left(\gamma_{s}\right)$ is quantified as the ratio of the maximum diaphragm deflection to average drift of adjoining lateral load-resisting system, under uniform distributed lateral load along the diaphragm. This study considered a relatively wide range of different degrees of diaphragm flexibility.

(3) The structures were exposed to unidirectional $(y$ direction) earthquake excitations. Models have different degrees of stiffness and strength eccentricity only in the perpendicular direction ( $x$ direction) to seismic loading. However, according to the description of the previous sections, the 
TABLE 4: Natural periods of individual diaphragms and corresponding values of flexibility in base symmetric structure.

\begin{tabular}{lcc}
\hline Number & $T_{d}(\mathrm{sec})$ & $\gamma_{s}$ \\
\hline$(1)$ & 0.000 & 0.000 \\
$(2)$ & 0.027 & 0.031 \\
$(3)$ & 0.038 & 0.062 \\
$(4)$ & 0.056 & 0.125 \\
$(5)$ & 0.089 & 0.250 \\
$(6)$ & 0.142 & 0.500 \\
$(7)$ & 0.191 & 0.750 \\
$(8)$ & 0.235 & 1.000 \\
$(9)$ & 0.276 & 1.250 \\
$(10)$ & 0.314 & 1.50 \\
$(11)$ & 0.382 & 2.00 \\
$(12)$ & 0.441 & 2.50 \\
$(13)$ & 0.494 & 3.00 \\
$(14)$ & 0.587 & 4.00 \\
$(15)$ & 0.667 & 5.00 \\
$(16)$ & 0.740 & 6.00 \\
$(17)$ & 0.806 & 7.00 \\
$(18)$ & 0.867 & 8.00 \\
\hline
\end{tabular}

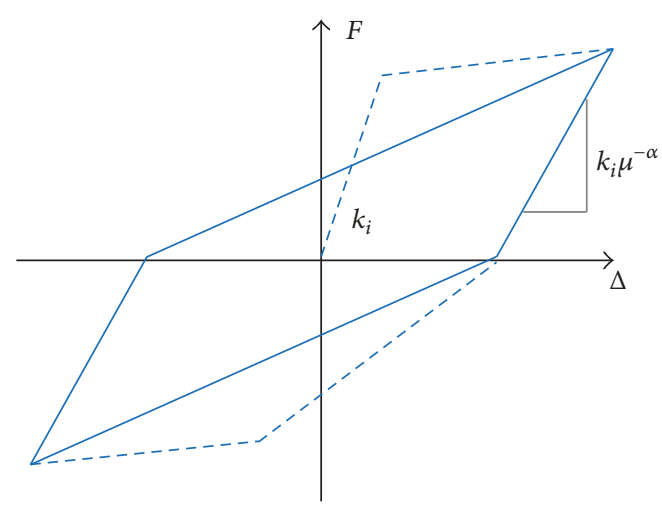

FIGURE 5: Takeda thin hysteresis rule [36].

distance between the centers of stiffness and strength in all asymmetric models were considered the same. The mass of walls was neglected as compared to the diaphragm mass, and the diaphragm mass is uniformly distributed on its surface. Therefore, in all the models, the mass center matches the geometric center of the diaphragm.

(4) The out of plane stiffness and strength of the walls were neglected. The local and out of plane failures of the walls were avoided. The dependence of the strength of the walls to the axial force was neglected. The force-displacement relationship of concrete shear walls was modeled using the thin Takeda hysteresis model (Figure 5).

This model is commonly used to simulate the seismic behavior of reinforced concrete shear walls and columns [36]. The postyield stiffness was considered zero on all walls. It is notable that, in this study, the collapse potential of resisting elements was not considered in analytical modeling. A 5\% damping ratio proportional to the mass was included in the analyses.

Analytical modeling and nonlinear inelastic dynamic time-history analyses were performed using the OpenSees software package [34]. Due to the long period of time needed to analyze each of the models, the facilities of DesignSafe [37] were used.

After the finite elements modeling, the structures were subjected to seven unidirectional records of far-field earthquakes. The earthquake records considered were related to the same soil conditions with a minimum magnitude of 6 and a minimum PGA of $0.15 \mathrm{~g}$ (Table 5). The displacement and pseudo-acceleration spectra of the used records are presented in Figure 6. In dynamic time-history analyses, each record was scaled for two different earthquake intensities with PGA $=0.35 \mathrm{~g}$ for Design Basis Earthquake (DBE) and PGA $=0.70 \mathrm{~g}$ for Maximum Considered Earthquake (MCE).

\section{Results of Analyses}

5.1. The Effect of Structure Asymmetry on the Deformations of Flexible Diaphragms. According to the dimensions of the diaphragms and modeling of the axial stiffness of the primary beams, and also applying the unidirectional seismic loading in this study, the investigations showed that one can decompose the deformation of each diaphragm into four components with a very accurate approximation: (1) the translation of the diaphragm as a rigid mode $\left(\delta_{t}\right),(2)$ the rotation of the diaphragm as a rigid mode $\left(\delta_{r}\right)$, and (3) shear-dominant deformation $\left(\delta_{s}\right)$ and bending-dominant deformation $\left(\delta_{d}\right)$ (Figure 7). It should be noted that sheardominant and bending-dominant deformations are the overall deformation shapes of the diaphragm and is not related to the components of the deformation of a Timoshenko beam.

Majority of these deformations can be calculated using the displacement recorders considered in the analytical models (Figure 4) for each of the diaphragms (DPH):

$$
\begin{aligned}
\text { DPH 1: } \quad \delta_{t} & =0.5\left(u_{1}+u_{2}\right) \\
\delta_{r} & =\frac{l\left(v d_{1}-v d_{2}\right)}{b} \\
\delta_{s} & =\left(u_{2}-u_{1}\right)-\delta_{r} \\
\delta_{d} & =u_{d 1}-\delta_{t} \\
\text { DPH 2: } \quad \delta_{t} & =0.5\left(u_{2}+u_{3}\right) \\
\delta_{r} & =\frac{l\left(v d_{3}-v d_{4}\right)}{b} \\
\delta_{s} & =\left(u_{3}-u_{2}\right)-\delta_{r} \\
\delta_{d} & =u_{d 2}-\delta_{t} .
\end{aligned}
$$

In Figure 8, the mean of maximum values of $\delta_{t}, \delta_{r}, \delta_{s}$, and $\delta_{d}$ for diaphragms of model 6 (which has only stiffness eccentricity) for DBE earthquakes is shown: (a) elastic response and (b) inelastic response. For comparison, the results of the 
TABLE 5: Earthquake records used in dynamic time-history analysis.

\begin{tabular}{|c|c|c|c|c|c|c|c|c|}
\hline Event & Year & Station & $M_{w}$ & Mechanism & Closest distance $(\mathrm{m})$ & $V_{s 30}(\mathrm{~m} / \mathrm{s})$ & PGA (g) & Duration (sec) \\
\hline Imperial Valley-06 & 1979 & Cerro Prieto & 6.53 & Strike slip & 15.19 & 471.53 & 0.168 & 36.27 \\
\hline N. Palm Springs & 1986 & San Jacinto, Soboba & 6.06 & Reverse oblique & 22.96 & 447.22 & 0.254 & 20.09 \\
\hline Cape Mendocino & 1992 & Shelter Cove Airport & 7.01 & Reverse & 26.51 & 518.98 & 0.228 & 30.5 \\
\hline Chi-Chi, Taiwan & 1999 & TCU045 & 7.62 & Reverse oblique & 26 & 704.64 & 0.507 & 35.095 \\
\hline San Fernando & 1971 & Castaic, Old Ridge Route & 6.61 & Reverse & 19.33 & 450.28 & 0.320 & 20.27 \\
\hline Kern County & 1952 & Taft Lincoln School & 7.36 & Reverse & 38.42 & 385.43 & 0.159 & 47.64 \\
\hline Manjil, Iran & 1990 & Qazvin & 7.37 & Strike slip & 49.97 & 302.64 & 0.184 & 35.99 \\
\hline
\end{tabular}

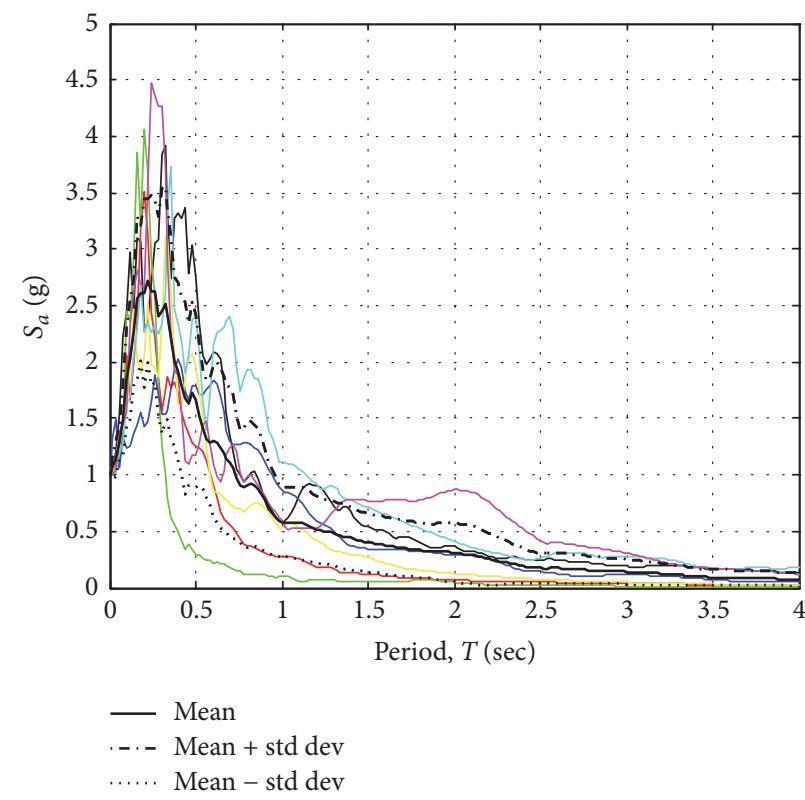

(a)

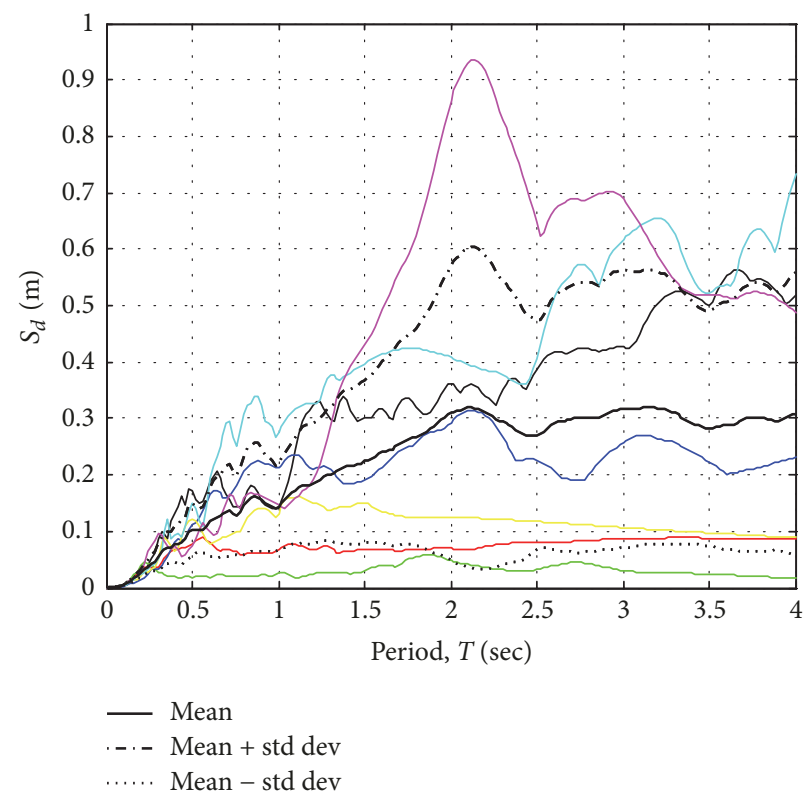

(b)

FIGURE 6: The response spectra of records $(\xi=0.05)$ : (a) pseudo-acceleration and (b) displacement. Thin curves are the response spectra of earthquake records in Table 5.

corresponding deformations in the symmetric structures are also drawn as a continuous line.

As shown, the diaphragms deformations of the asymmetric structure, especially in the inelastic analysis, are very similar to those of the symmetric structure. The only major difference is the lack of rotational deformation of the diaphragms in the symmetric structure. Another significant point is the importance of the shear deformation and its growth for the inelastic range, and even for the symmetric structure. This can be due to the fact that, with increase in the flexibility, the central wall of the structure with a greater tributary area than the two side walls absorbs more seismic load and thus experiences more deformations than the lateral elements, and this increases the shear deformation of the diaphragms.

Reducing the translational and rotational rigid modes and, in contrast, the increase in bending and shear deformations of the diaphragm which occurs with increase in diaphragm flexibility clearly reflect a change in the seismic behavior of the structure. Although this change in behavior (changing the mode from the rigid modes to the deformational modes) can lead to a reduction in engineering demands in some LLREs, another issue that needs to be fully addressed is the growth of the demand for deformational modes in the diaphragms, which usually has no capability for large deformations.

The mean of maximum values of the deformations for the diaphragms of model 2 (which has only strength eccentricity), at inelastic range and for DBE earthquakes, is depicted in Figure 9. For comparison, the results of the corresponding deformations in the symmetric structure are also drawn in the form of a dashed line.

As shown, the modes of rotational motion and bending deformation of the two diaphragms of the asymmetric structures are very similar. Also, the bending deformation of the diaphragms corresponds to their values in a symmetric structure. The major difference in the deformation of the neighbor diaphragms is the translation and shear deformations modes. It can be clearly seen that the values of shear deformation for the weak side diaphragm (DPH1) of the asymmetric structure 


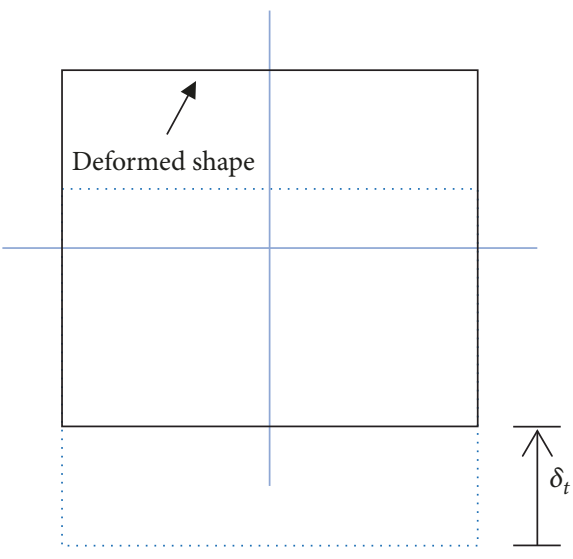

(a) Rigid mode: translation

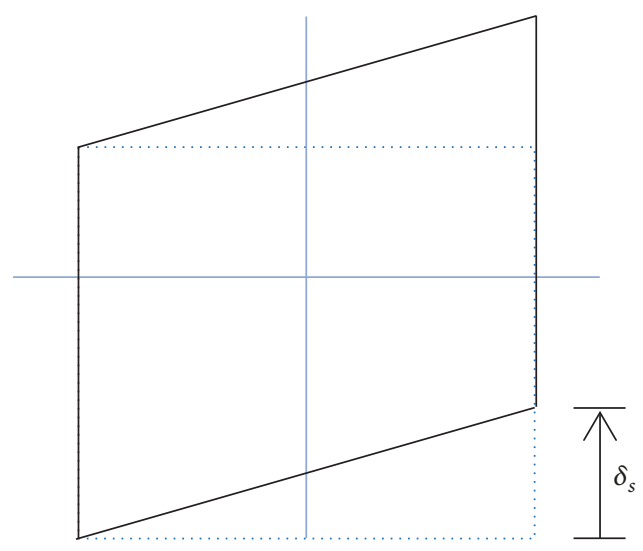

(c) Deformational mode: shear

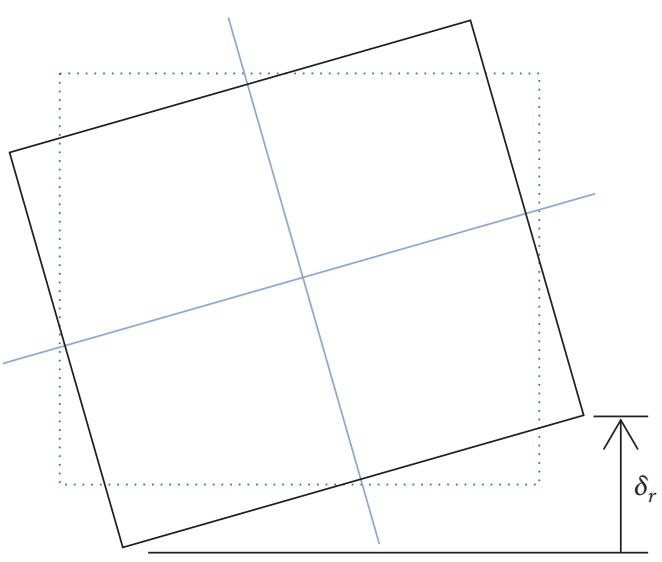

(b) Rigid mode: rotation

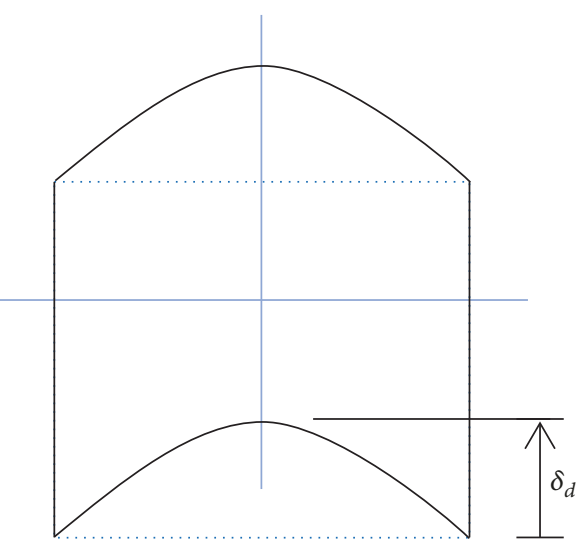

(d) Deformational mode: bending

FIGURE 7: Deformation components of the diaphragm.

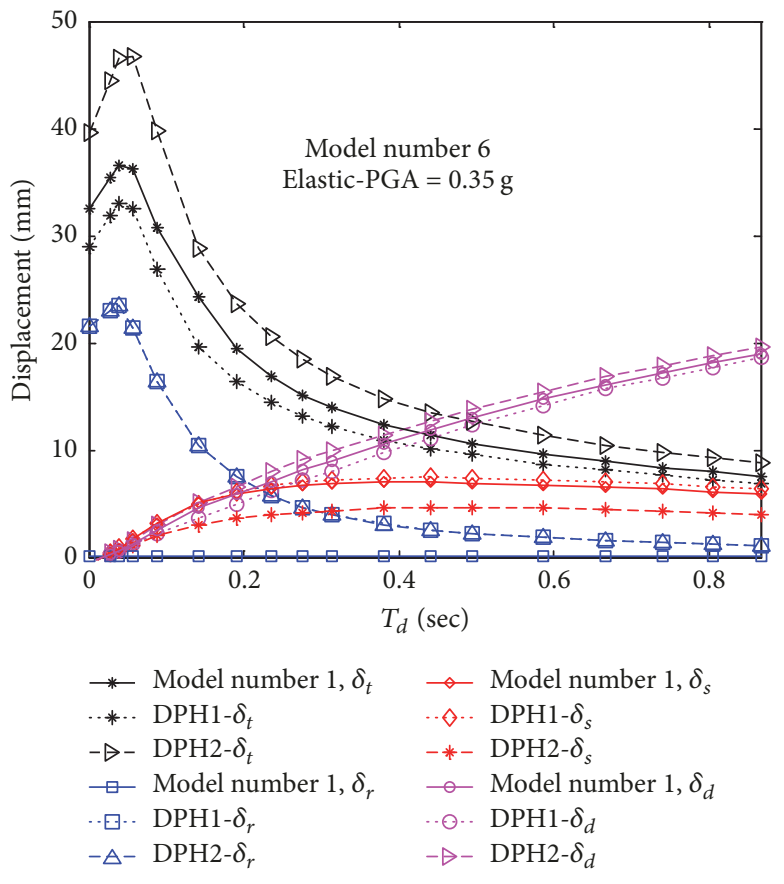

(a)

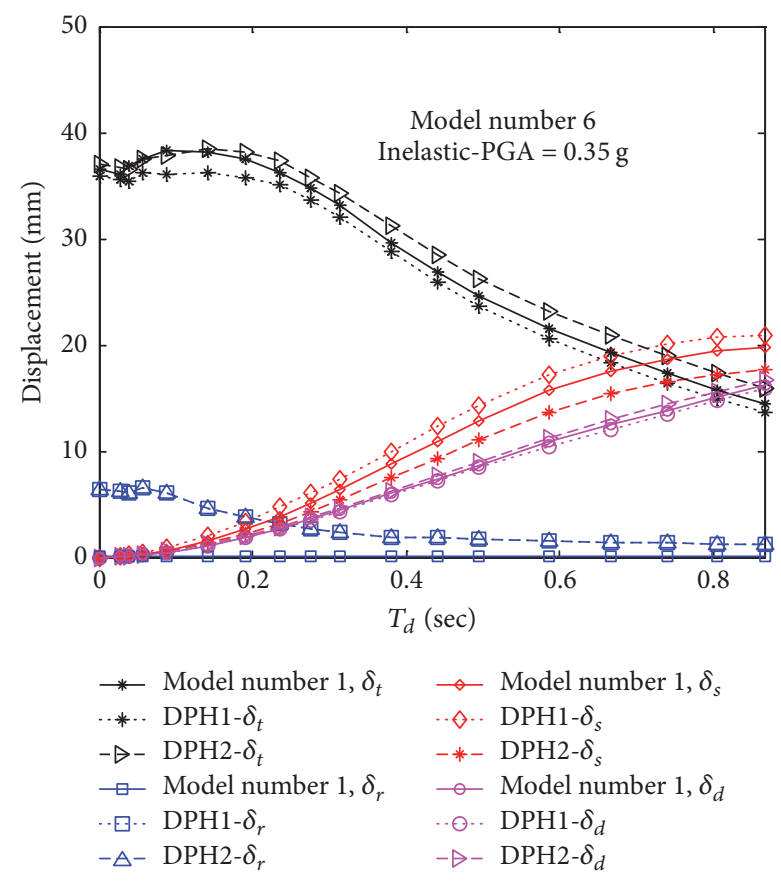

(b)

FIGURE 8: Deformation components of diaphragms for model 6 in DBE earthquakes: (a) elastic and (b) inelastic. 

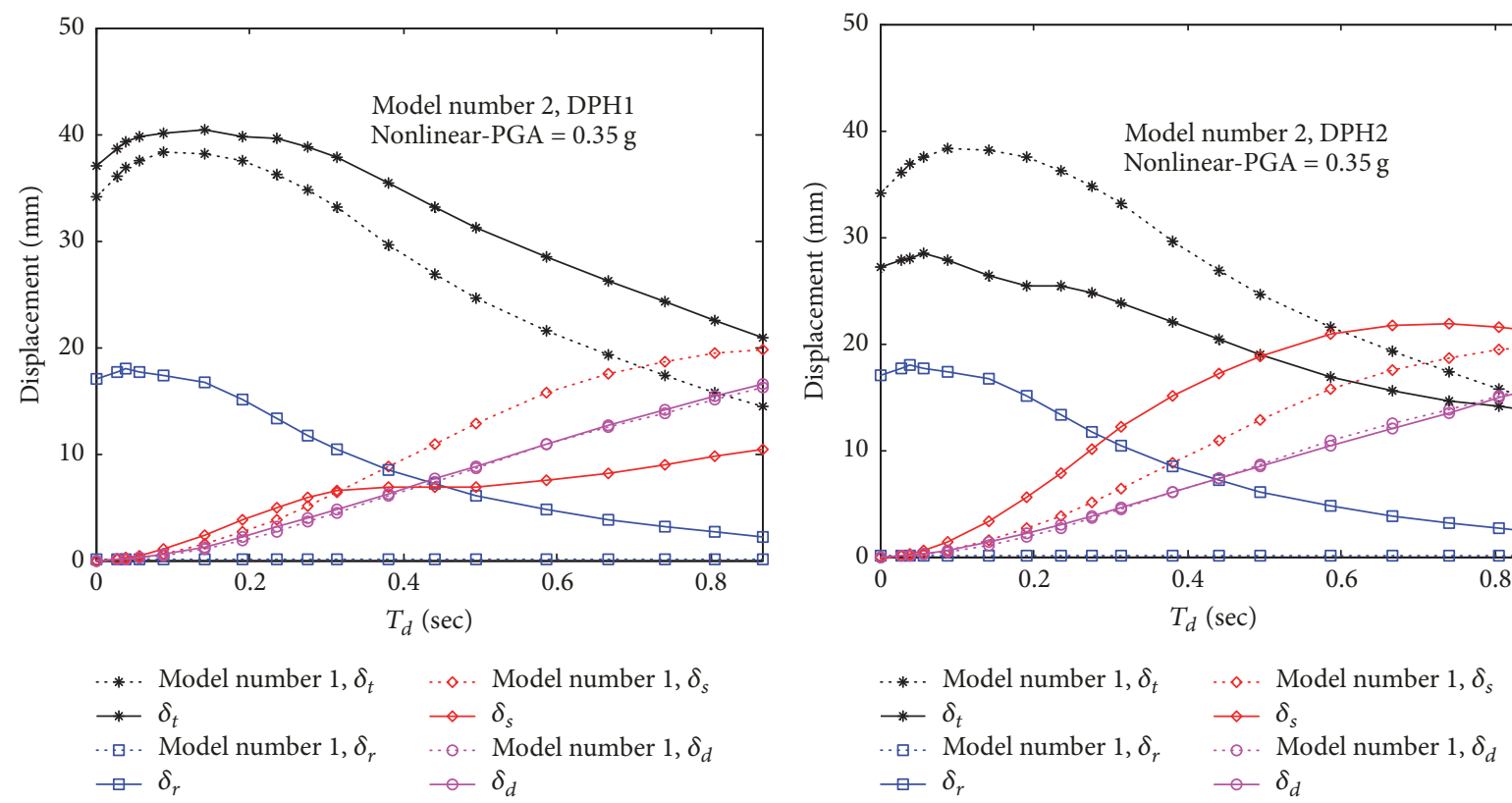

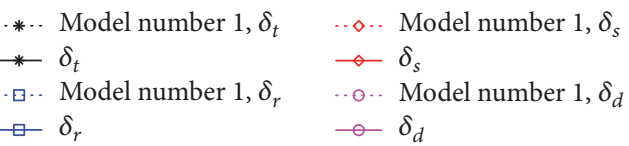

(a) (b)

FIGURE 9: Deformation components of diaphragms for model 2 in DBE earthquakes: (a) DPH1 and (b) DPH2.

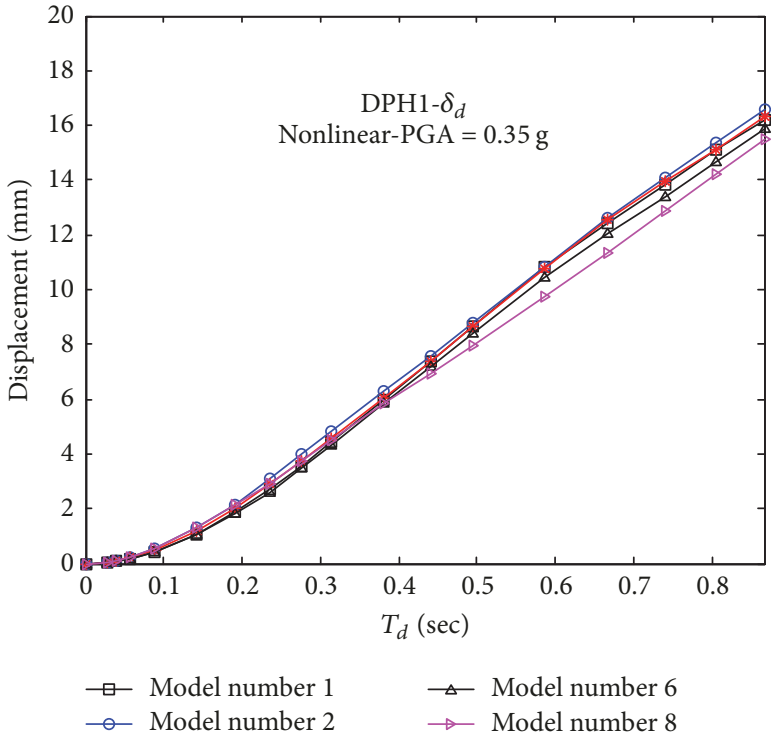

(a)

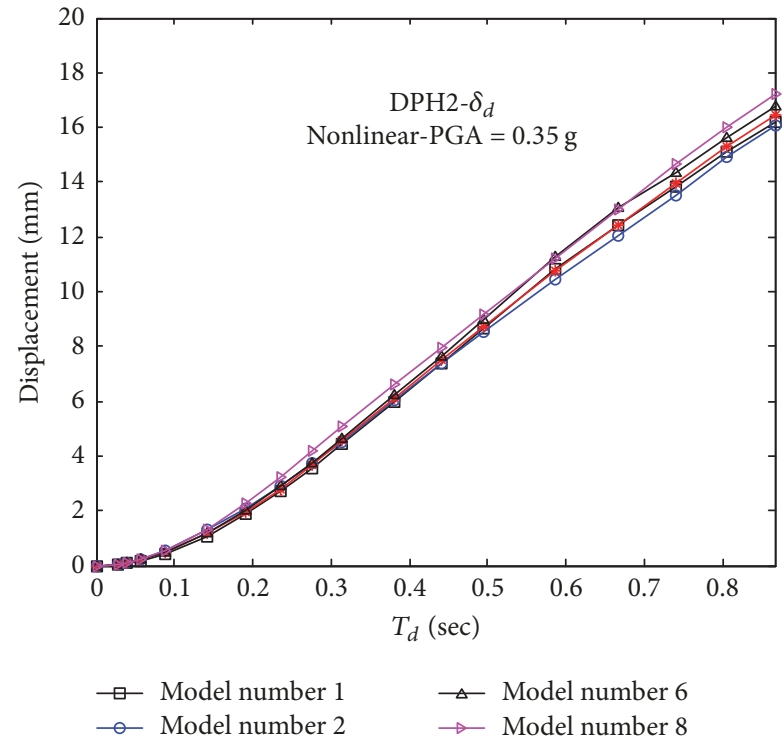

(b)

FIGURE 10: Bending-dominant deformation of diaphragms in DBE earthquakes: (a) DPH1 and (b) DPH2.

are lesser than that of the strong side diaphragm (DPH2). This phenomenon can be interpreted as the concentration of shear-dominant deformations in the strong side diaphragm of the structure which is accompanied by the concentration of the translational motion (rigid mode) on the weak side diaphragm of the structure.

Therefore, it can be concluded that, by increasing the diaphragm flexibility, the rigid modes of the translational and rotational motions of the diaphragm are reduced and the diaphragm shear and bending deformations grow. The growth of the diaphragm shear deformation approximately stops after a certain degree of flexibility, but the growth of the bending deformation of the diaphragm is continuous. The bending deformation of adjacent diaphragms in different asymmetric structures is very close to each other and similar to that in the symmetric structure (Figure 10), 

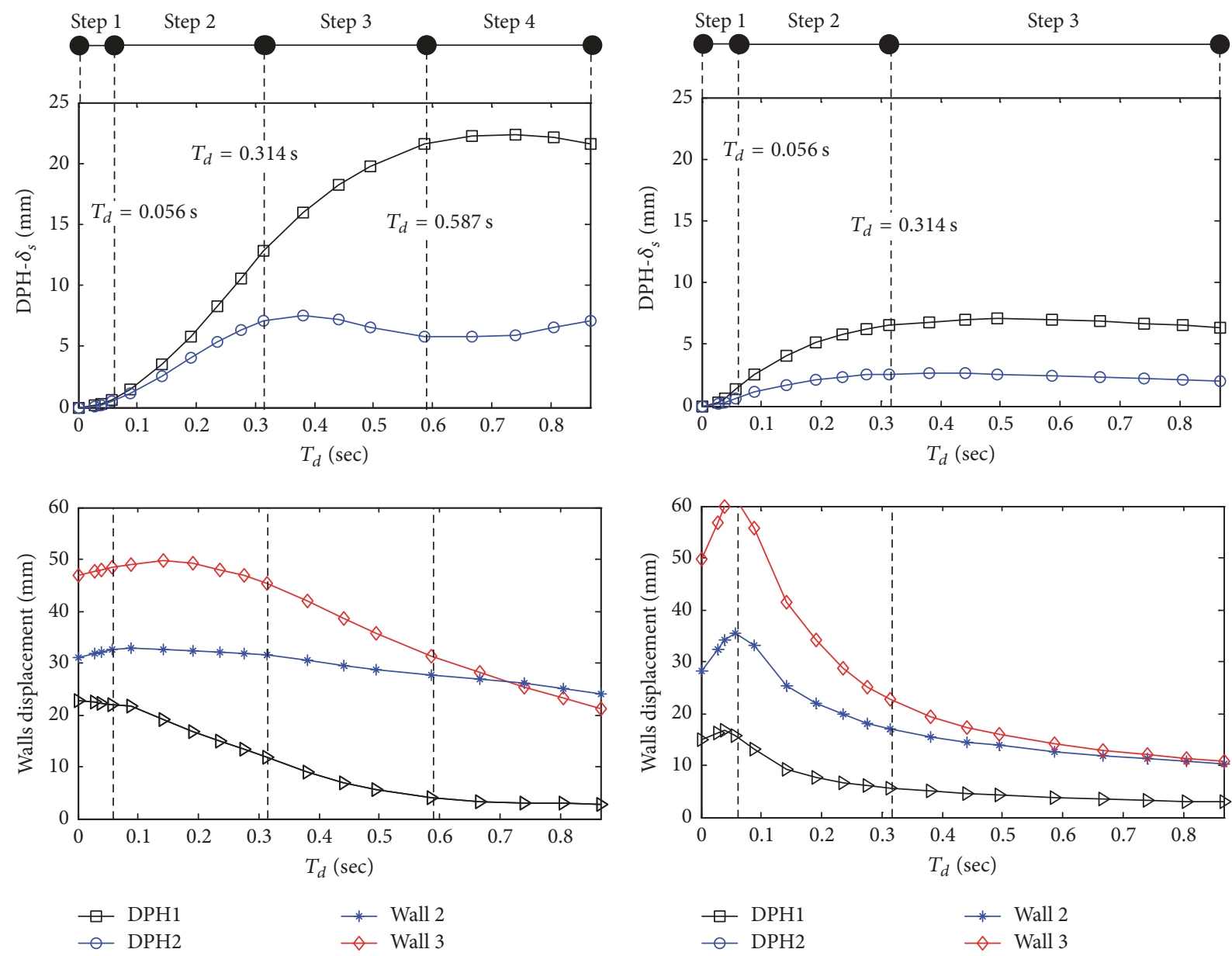

(a)

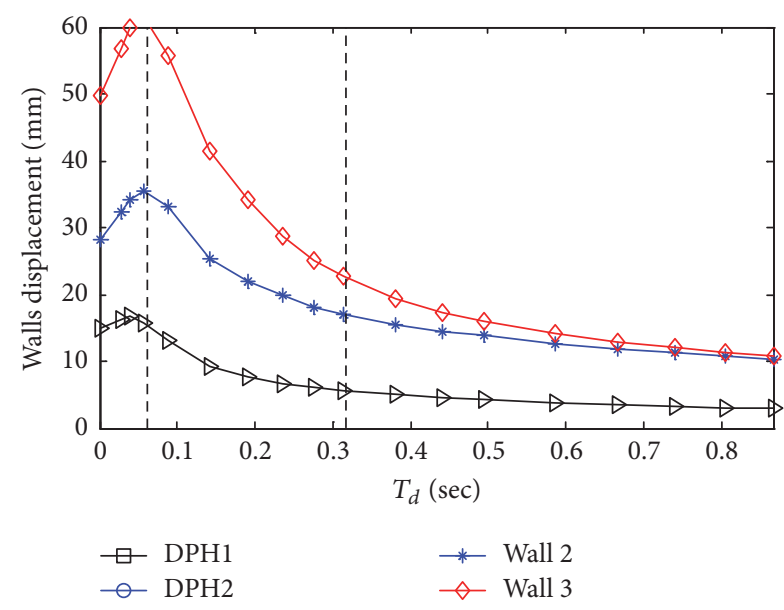

(b)

FIGURE 11: Qualitative classification of the asymmetric structures behavior for model 8 in DBE earthquakes: (a) inelastic and (b) elastic.

while the shear deformation of adjacent diaphragms of asymmetric structures is very different and the concentration of shear deformations in one of the diaphragms is observed.

\subsection{Qualitative Classification of the Asymmetric Structures} Behavior Based on Degree of Diaphragm Flexibility. As a result of the shear deformation sensitivity of the diaphragms to structure asymmetry and the degree of flexibility, the shear deformation can be a better criterion for measuring the performance of structure diaphragms. The shear deformations of diaphragms and displacement of walls for model 8 are depicted in Figure 11: (a) elastic and (b) inelastic. In accordance with Figure 11(a), for the inelastic range, the behavior of the considered asymmetric structures can be categorized qualitatively into four steps based on their degree of diaphragm flexibility.

Step 1 (rigid diaphragms). The diaphragm's shear deformation is negligible in comparison with the rotational and translational motions.
Step 2 (semirigid diaphragms). In this step, by increasing the diaphragm flexibility, the shear deformation of both structure diaphragms continuously grows at a fast rate.

Step 3 (fixed shear-dominant response in the weak side diaphragm (DPH2)). Starting the third step, with increase in diaphragm flexibility, the shear deformation of the weak side diaphragm remains almost constant, while the shear deformation of the strong side diaphragm continues to grow. In this step, the displacement of the central wall has almost a constant trend.

Step 4 (fixed shear-dominant response on both diaphragms of the structure). In this step, the shear deformation growth of the strong side diaphragm will stop and will have a constant trend. In this step, displacement of the strong wall has an approximately constant trend.

In elastic structures, given that the elements response is only in the elastic range, only three steps of behavior can be identified. (1) rigid diaphragm, (2) semirigid diaphragms, and (3) fixed shear-dominant response on both 

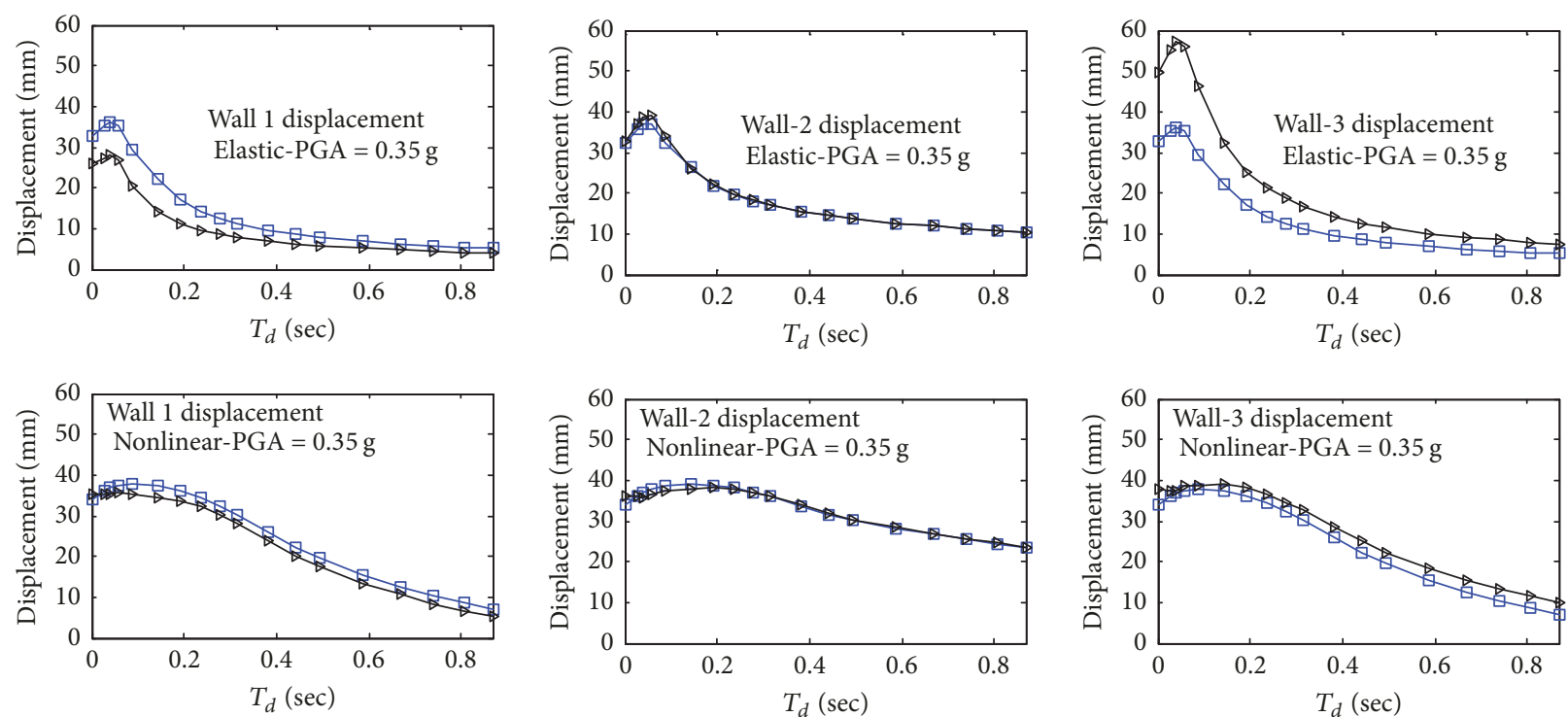

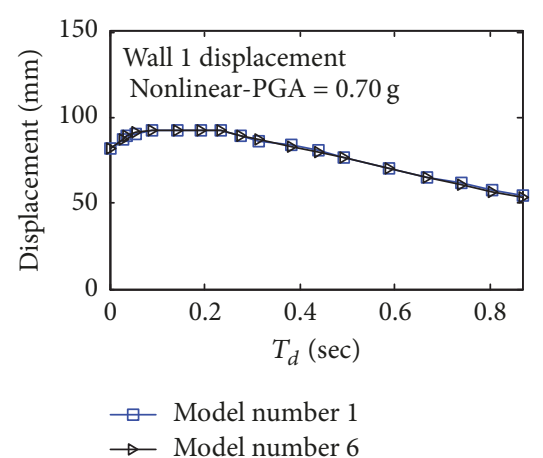

(a)

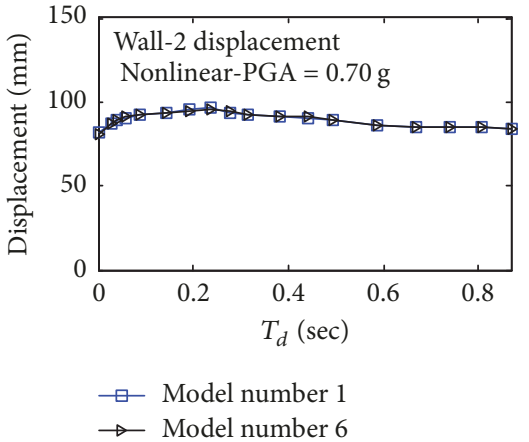

(b)

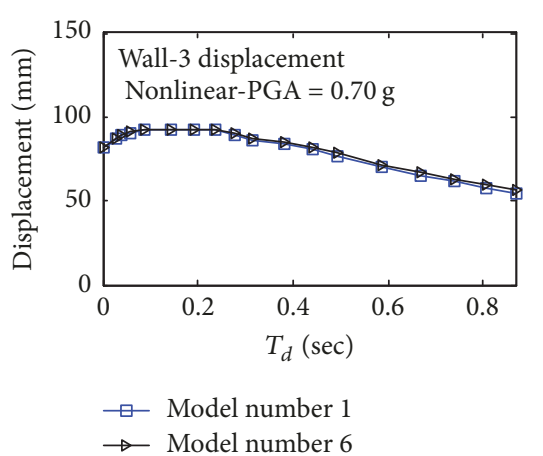

(c)

FIGURE 12: Walls displacements of model 6 in DBE and MCE earthquakes: (a) wall 1 (left side, stiff), (b) wall 2 (central), and (c) wall 3 (right side, flexible).

diaphragms of the structure. It should be noted that, in the third step of elastic structures, the convergence of the weak wall displacement to the central wall displacement is mainly due to decrease in the rotational deformation of the weak side diaphragm. From this discussion, it can be concluded that, first, the behavior of the structure diaphragms is not only a function of the diaphragm flexibility, but the overall configuration of the structure and configuration of the centers. It should be noted that the center of strength has the most significant effect on the behavior of diaphragms. Second, while the bending deformation of the diaphragms in all structures is almost identical, the sheardominant deformation gives clearer criteria of diaphragm performance.

5.3. Effect of Diaphragm Flexibility on LLREs of Asymmetric Structures. In Figures 12(a), 12(b), and 12(c), respectively, the mean of maximum displacement of walls 1 (stiff side), 2 (central), and 3 (flexible side), which are the main walls in the direction of seismic loading, for model 6 (which has stiffness eccentricity and strength symmetry) is shown for different degrees of diaphragm flexibility $\left(T_{d}\right)$. The first row corresponds to the elastic structure response under DBE earthquakes, while the second and third rows, respectively, represent the results of nonlinear analyses in DBE and MCE earthquakes. In all the diagrams, the displacements of the corresponding walls in the symmetric structure (model 1) are also presented for comparison.

In general, by increasing the diaphragm flexibility, the displacement of the LLREs decreases in both symmetric and asymmetric structures. According to the acceleration response spectra of earthquakes records, rigid diaphragm models fall into a resonance region, while their flexible diaphragm structures fall into the descending branch of the spectra; this explains why those demands are considerably reduced. It is notable that an increase in flexibility result in a higher participation of the tributary area in lateral forces distribution and, consequently, less reduction in demands can be seen for the central walls.

As shown, the overall asymmetric structure response is similar to the symmetric structure response and the asymmetry has little effect on the displacements of the walls. 


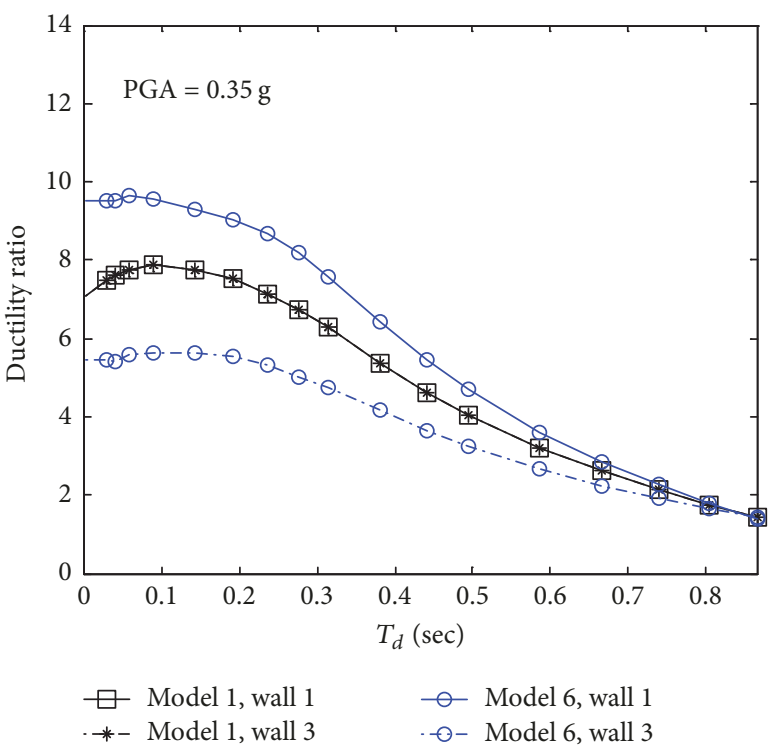

(a)

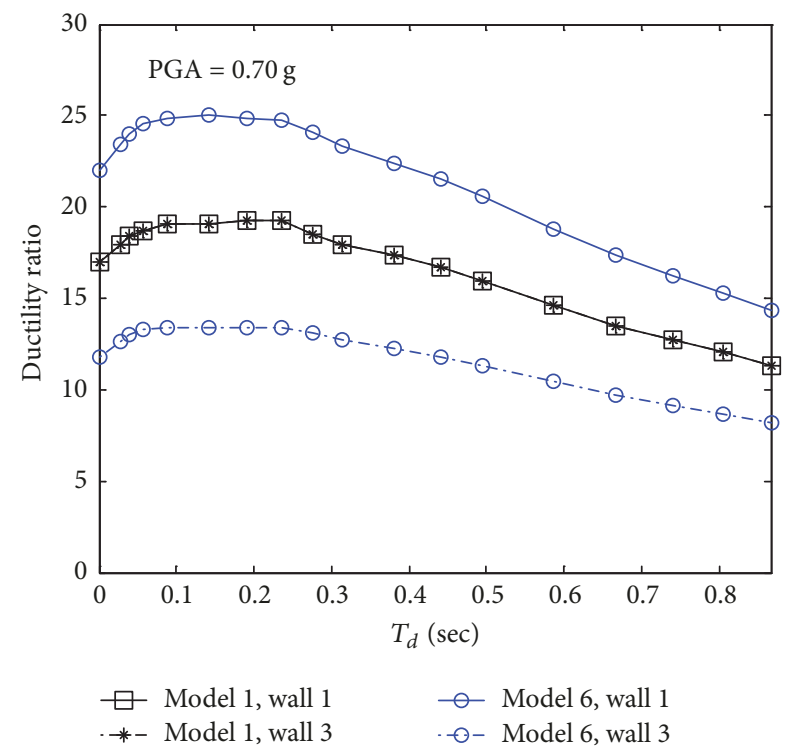

(b)

FIGURE 13: Ductility demands of stiff (wall 1) and flexible (wall 3) walls of the model 6: (a) DBE earthquakes (0.35 g) and (b) MCE earthquakes $(0.70 \mathrm{~g})$.

In the elastic asymmetric structure, the flexible side wall shows more displacement compared to the same wall in the symmetric structure, and the opposite is true in the stiff side wall. In general, it can be said that the stiffness eccentricity only in elastic analyses and in low flexibilities (rigid and semirigid diaphragms) increases displacement of the flexible side wall relative to the similar symmetric structure. With increase in the diaphragm flexibility or the intensity of the earthquake (yield level of elements), the effect of the stiffness eccentricity on structure displacements quickly decreases. Similar conclusions were provided in previous studies [6].

The mean of maximum ductility demands for end walls of model 6 in DBE and MCE earthquakes for various degrees of flexibility $\left(T_{d}\right)$ is shown in Figures 13(a) and 13(b), respectively. The results of the corresponding walls in the symmetric structure (model 1) are presented for comparison.

As shown, in contrast to the displacement responses, the stiff side wall of the asymmetric structure (wall 1) experiences more ductility demands than that of the symmetric structures, while the opposite is true for the flexible side wall (wall 3). Higher ductility demand values can be observed in semirigid diaphragm structures and by increasing the flexibility, the ductility demands converge to its values in symmetric structures. This phenomenon actually represents a more uniform distribution of damage in the asymmetric structure walls by increasing the flexibility. As the intensity of the earthquake increases, variation in the ductility demands of the asymmetric structure walls becomes closer to that of the symmetric structure. In general, the stiffness eccentricity, in contrast to the displacement response of walls, affects the ductility demand of asymmetric structure walls and increases the ductility demands in stiff structural elements. By increasing the diaphragm flexibility, the ductility demands of the LLREs are also reduced.

In Figures 14(a), 14(b), and 14(c), respectively, the mean of maximum displacement of walls 1 (weak side), 2 (central), and 3 (strong side) for model 2 (which has strength eccentricity and stiffness symmetry) is shown for different degrees of flexibility $\left(T_{d}\right)$. The first and second rows respectively represent the results of nonlinear analyses in the DBE and MCE earthquakes. In all the diagrams, displacements of the corresponding walls in the symmetric structure (model 1) are also presented for comparison.

As shown, the overall responses of asymmetric structures are similar to the responses of symmetric structures. In contrast to structures with stiffness eccentricity, in this group of structures, flexibility has a significant effect on the displacement of the end walls. In this model, the weak side wall shows more displacements than similar symmetric structure, and the opposite is true for the strong side wall. Also, by increasing the diaphragm flexibility or the intensity of the earthquake (the yield level of elements), the effect of strength eccentricity will not be diminished on the displacement of structure walls, so that, in structures with a very flexible diaphragm, the effect of the strength eccentricity on the displacement of the walls is quite significant.

The mean of maximum ductility demand for end walls of model 2 (which has strength eccentricity and stiffness symmetry) in DBE and MCE for different degrees of flexibility $\left(T_{d}\right)$ is shown in Figures 15(a) and 15(b), respectively.

Generally, by increasing the diaphragm flexibility, the ductility demands of the walls in the asymmetric structure decrease. As shown, the weak side wall of the asymmetric structure (wall 1) experiences more ductility demands than 

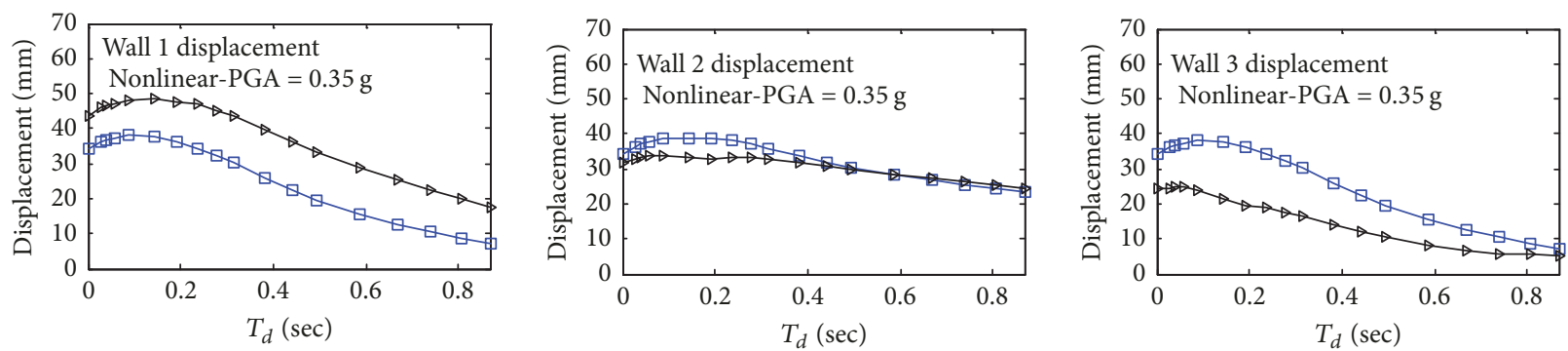

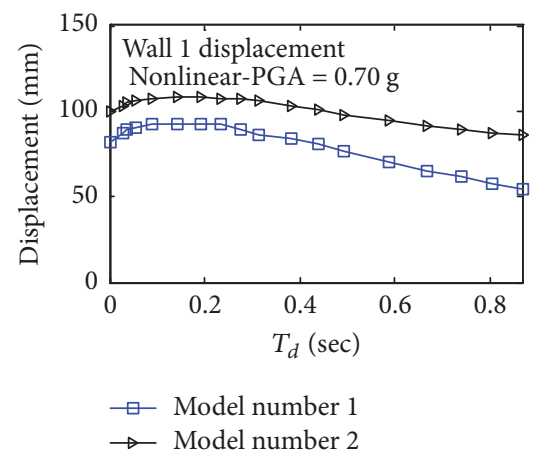

(a)

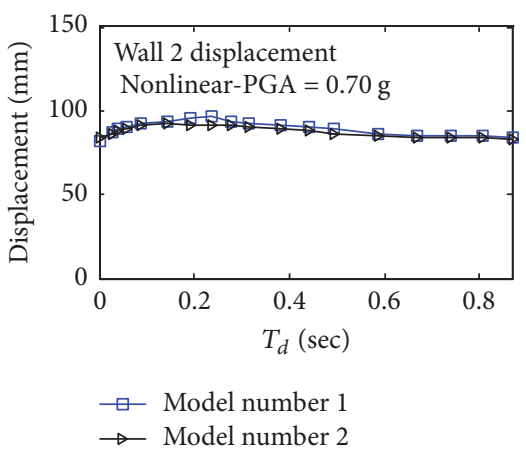

(b)

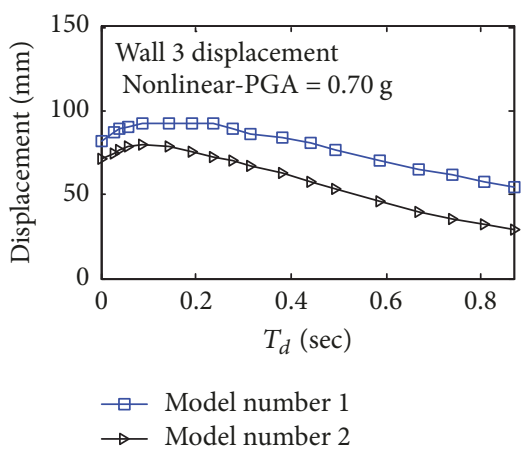

(c)

FIGURE 14: Walls displacements of model 2 in DBE and MCE earthquakes: (a) wall 1 (left side, weak), (b) wall 2 (central), and (c) wall 3 (right side, strong).

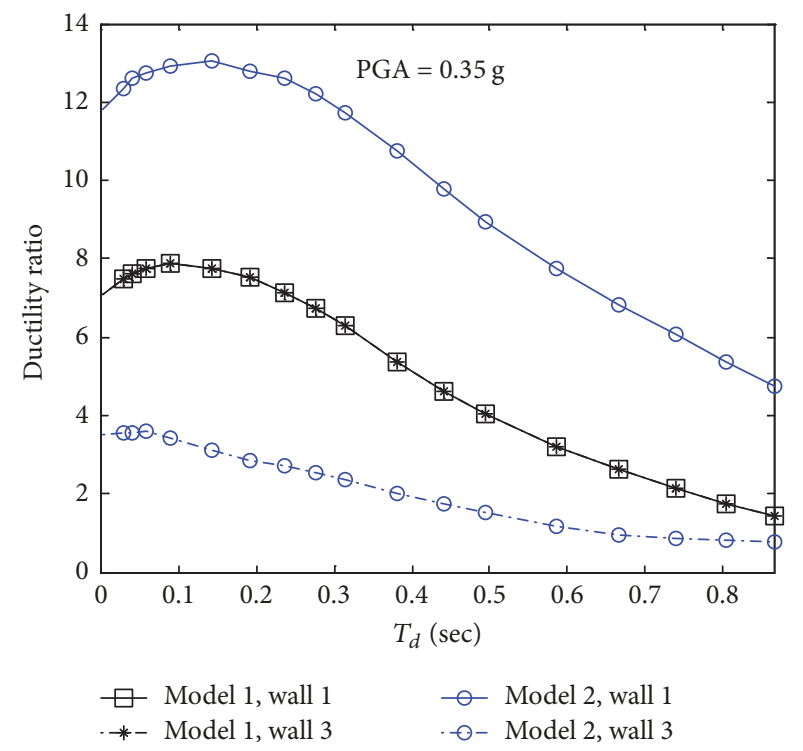

(a)

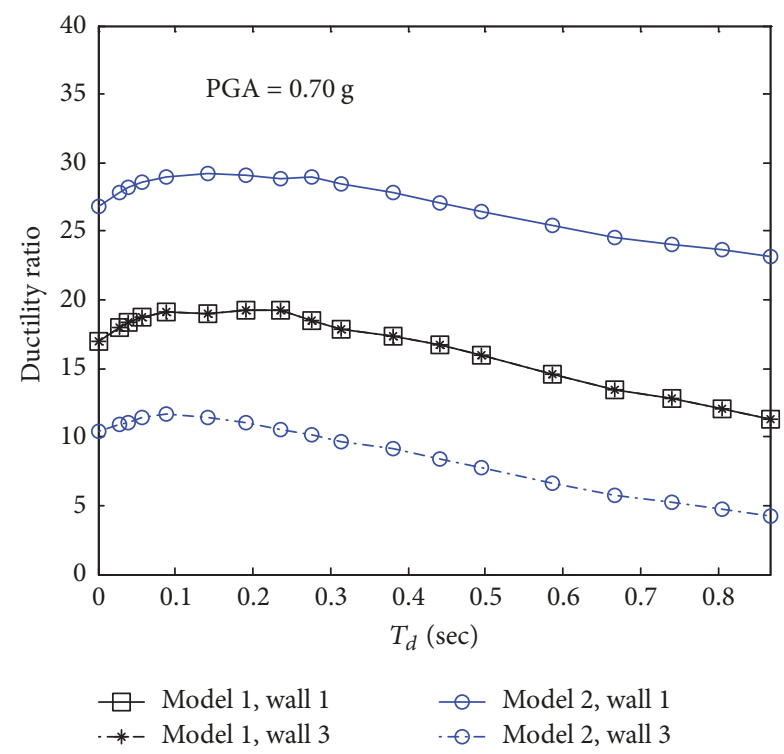

(b)

FIGURE 15: Ductility demands of weak (wall 1) and strong (wall 3) walls of model 2: (a) DBE earthquake (0.35 g) and (b) MCE earthquake $(0.70 \mathrm{~g})$.

symmetric structures, while the ductility demands in the strong side wall (wall 3) are less than that in the symmetric structure. A comparison of Figures 13 and 15 clearly shows that the influence of the strength eccentricity is much greater than that of the stiffness eccentricity on the displacement of walls in structures with flexible diaphragms. In structures with a very flexible diaphragm, the influence of strength eccentricity in the ductility demands of walls is clearly significant. As the intensity of the earthquake increases, the variation in the ductility demand of the asymmetric structure walls becomes closer to that of the symmetric structure. Contrary to the structures with stiffness eccentricity, 

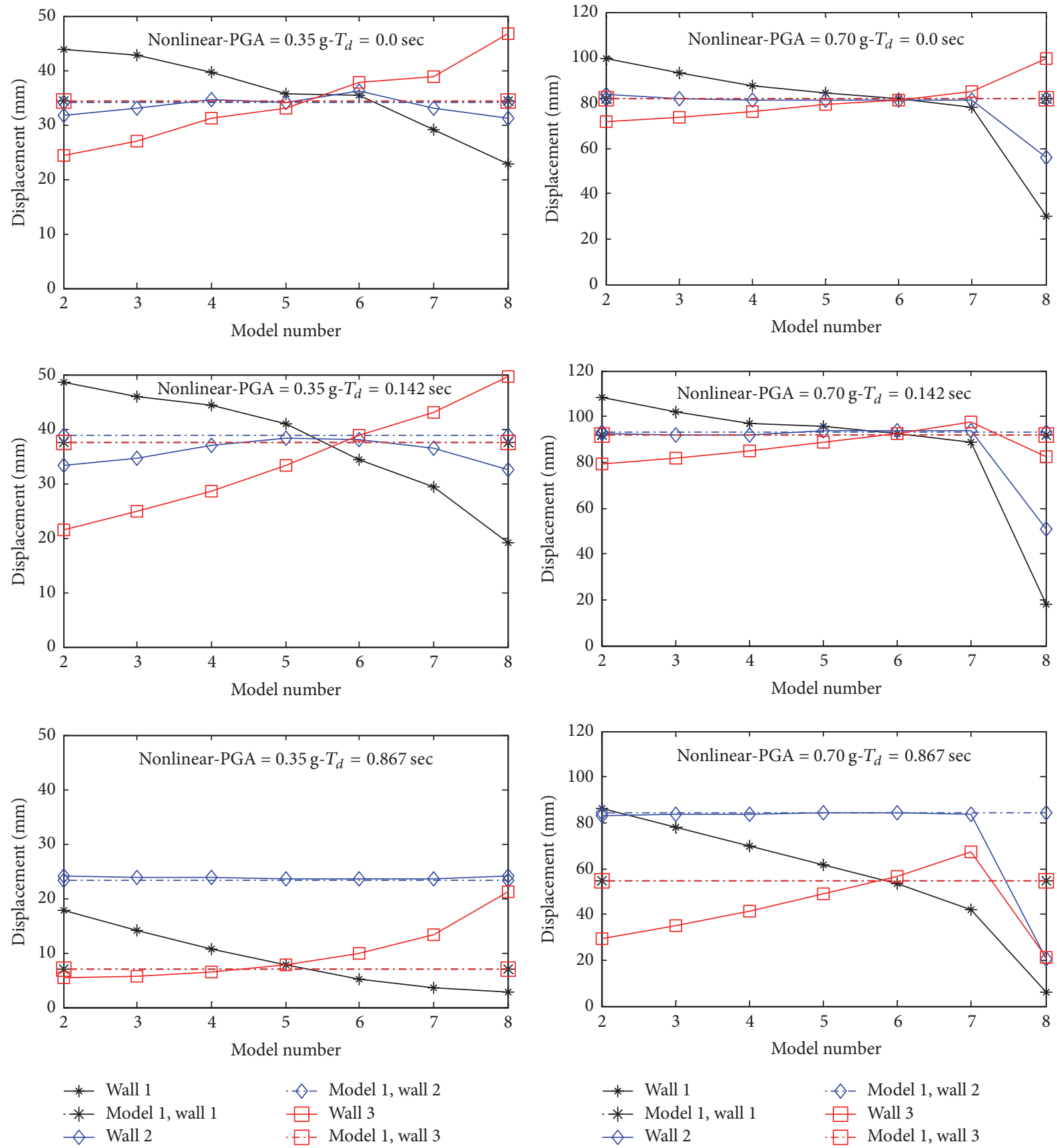

(b)

FIGURE 16: The mean of maximum displacements of walls in asymmetric structures: (a) DBE earthquakes (0.35 g) and (b) MCE earthquakes $(0.70 \mathrm{~g})$.

in structures with strength eccentricity, ductility demands converge less by increasing the flexibility, indicating a greater concentration of damage in the weak wall of the asymmetric structure.

5.4. Proper Configuration of Stiffness and Strength Centers in Structures with Flexible Diaphragm. The mean of the maximum displacement for walls of asymmetric models in $\mathrm{DBE}$ and MCE earthquakes is shown in Figures 16(a) and 16(b), respectively. The first row graphs refer to a completely rigid diaphragm structures $\left(T_{d}=0.0 \mathrm{sec}\right)$, the second row belongs to a semirigid diaphragm structure $\left(T_{d}=0.142 \mathrm{sec}\right)$, and the third row is for structures with quite a flexible diaphragm $\left(T_{d}=0.867 \mathrm{sec}\right)$. The displacement of the corresponding walls in the symmetric structures (model 1) is presented in the form of a dashed line and for comparison. The horizontal axis 
represents the number of structure models and displacements are presented only for the main walls that are exposed to seismic loads.

As shown in Figure 16(a), for DBE earthquakes in structures with a rigid diaphragm, the optimal configuration for reducing the mean displacement of all walls is related to model 5. This model has a balance configuration in which the center of the mass is located between stiffness and strength centers and the strength eccentricity is equal to one-quarter yield eccentricity. This conclusion is consistent with the findings of Aziminejad and Moghadam [26]. Considering other diagrams of Figure 16(a), which is related to structures with flexible diaphragms, it was observed that the degree of flexibility affects the optimal configuration. By increasing the flexibility from $T_{d}=0.0 \mathrm{sec}$ to $T_{d}=0.142 \mathrm{sec}$, the best configuration of the centers moves from models 5 to 6 , and then with increasing flexibility from $T_{d}=0.142 \mathrm{sec}$ to $T_{d}=0.867 \mathrm{sec}$, the optimal configuration continuously returns to model 5 . As seen in the structure with quite flexible diaphragm $\left(T_{d}=0.867 \mathrm{sec}\right)$, model 5 is the best configuration for minimizing the displacement of walls.

Another important point is that, in structures with a flexible diaphragm, the presence of only balance configuration cannot reduce the displacement of walls. Models 3 and 4, despite the presence of balance configuration, showed almost the same responses or even worse than the responses of model 7, which has no balance condition.

In MCE earthquakes, the optimal configuration of the centers is somewhat different for displacement of the walls. As shown in Figure 16(b), in structures with a rigid diaphragm, model 6 (which has strength symmetry) is considered as the optimal model. The displacement of walls in this model is consistent with that of the symmetric structure. This result is in accordance with the findings of Aziminejad and Moghadam [26]. With increase in the flexibility, while the responses of model 6 have a major similarity to symmetric structures in almost all the degrees of flexibility, in the flexibility of $T_{d}=0.142 \mathrm{sec}$ and higher values, model 8 offers displacements even less than that of the symmetric model. Therefore, this configuration can be considered as optimal configuration for the displacement of walls.

The mean of maximum ductility demand for walls of the asymmetric model in DBE and MCE earthquakes is shown in Figures 17(a) and 17(b), respectively.

As shown, in DBE earthquakes for a structure with a rigid diaphragm, the best configuration to reduce the ductility demand is the configuration of centers in model 8. By increasing the flexibility, the optimal configuration moves towards model 6 , so that in structures having quite a flexible diaphragm with $T_{d}=0.867 \mathrm{sec}$, model 6 is the best configuration of centers. The conditions in the MCE earthquakes vary slightly. In structures with a rigid diaphragm, the best configuration is between models 7 and 8 , while by increasing the flexibility, the optimum configuration moves to model 8. For flexibilities more than $T_{d}=0.142 \mathrm{sec}$, model 8 is considered as the best configuration for minimizing the walls ductility demands.

\section{Conclusion}

In this article, the effects of diaphragm flexibility on planasymmetric structures subjected to far-field ground motions are studied. A wide range of diaphragm flexibility in singlestory models with different configurations of mass, stiffness, and strength centers were considered. The analytical study resulted in the following major conclusions:

(1) By increasing the diaphragm flexibility, the intensities of rigid modes of diaphragms deformation are reduced, and bending and, especially, shear-dominant deformations grow. This clearly demonstrates changes in the mechanism of seismic forces absorption by asymmetric structure with a flexible diaphragm. Moreover, the concentration of shear-dominant deformations in some diaphragms of the plan-asymmetric structures is one of the most important weaknesses of these structures.

(2) Based on the shear deformation of the structure diaphragms, it is possible to qualitatively classify the behavior of asymmetric structures with various degrees of flexibility. This classification actually represents the single or coordinated function of the structural elements at various levels of diaphragm flexibility.

(3) Generally, increasing the diaphragm flexibility reduces the displacement and ductility demands of the LLREs in both symmetric and asymmetric structures. The changes observed in structural demands with diaphragm flexibility are strongly related to the considered ground motions. According to the acceleration response spectra of earthquakes records, rigid diaphragm models are put into the resonance region and, in contrast, their very flexible diaphragm structures fall in the descending branch of the spectra; this explains why those demands are considerably reduced.

(4) The effect of strength eccentricity on the demands of lateral walls is much greater than that of the stiffness eccentricity. High ductility demands in weak walls of structures with strength eccentricity indicate the concentration of more damage in these elements even in structures with quite flexible diaphragms.

(5) The proper configuration of centers in asymmetric structures with flexible diaphragm depends on three factors: degree of diaphragm flexibility, yield level of elements (earthquake intensity), and selected engineering demand parameter. In general, the proper configuration of centers in structures with flexible diaphragm is very similar to that in structures with a rigid diaphragm.

While this study focused on structures with concrete shear walls, the results can be used for other types of structures with different degrees of diaphragm flexibility. Also, it is expected that the general results of this study can be applicable in low-rise buildings because it is possible to ignore the participation of higher modes in these structures [19].

\section{Conflicts of Interest}

The authors declare that they have no conflicts of interest. 

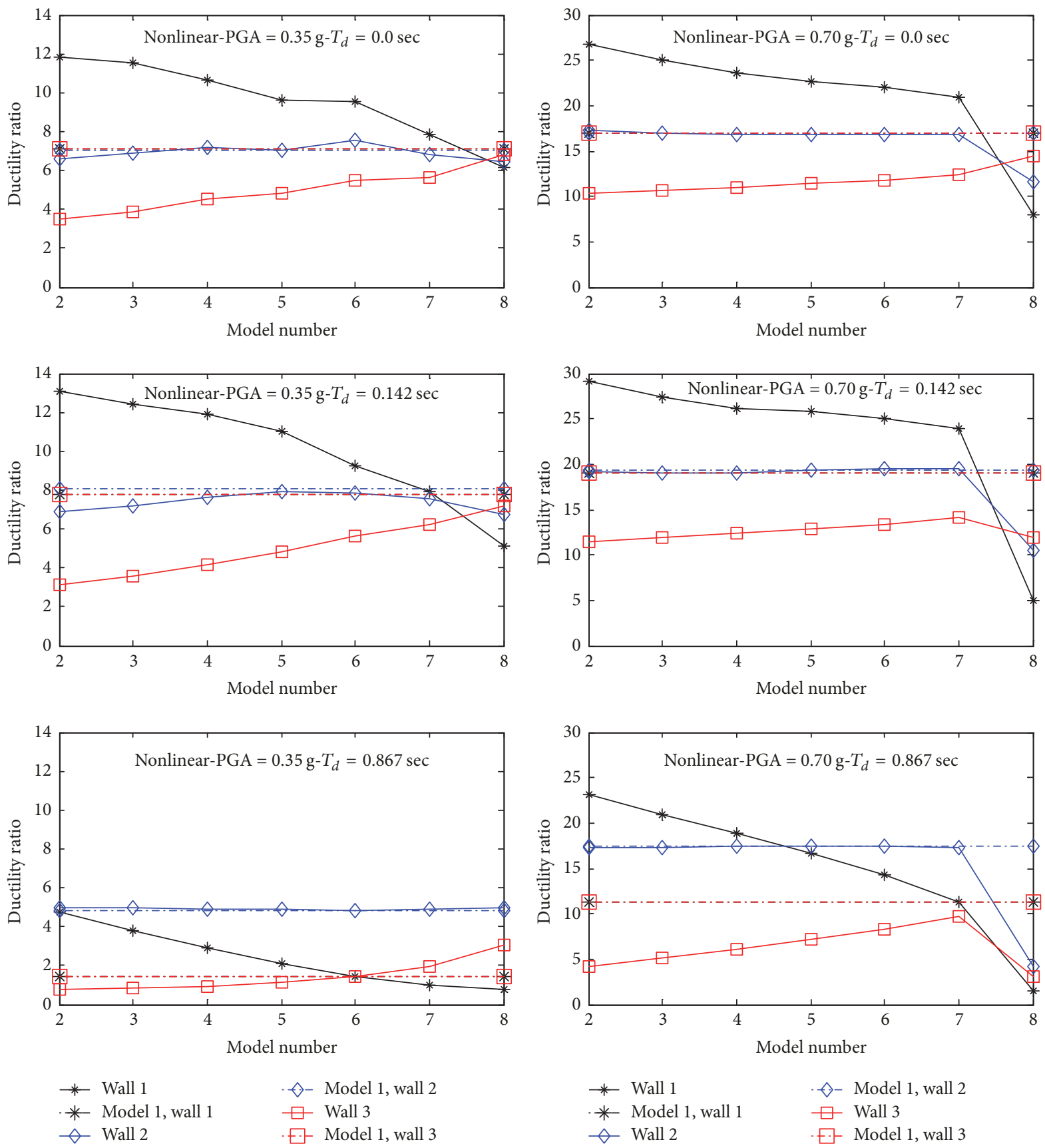

(a)
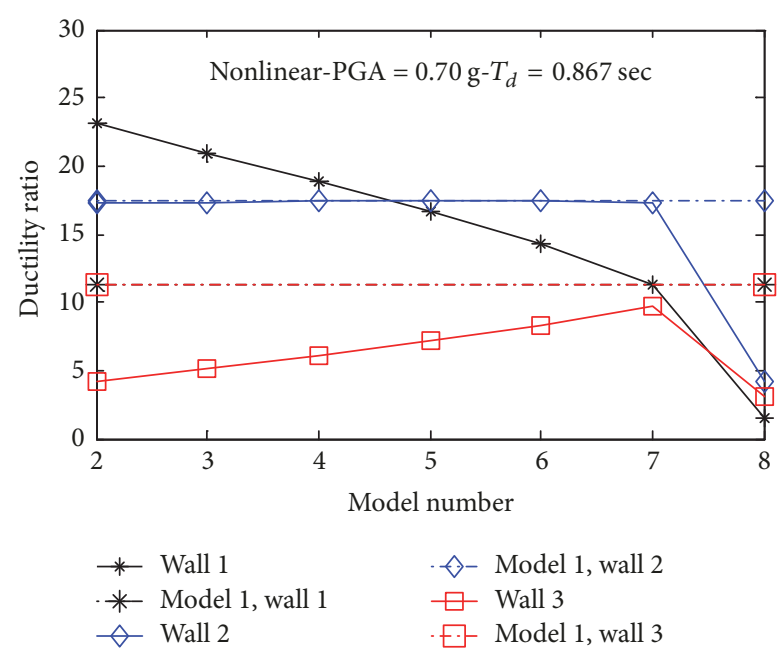

(b)

FIGURE 17: The mean of maximum ductility demands of walls in asymmetric structures: (a) DBE earthquake (0.35 g) and (b) MCE earthquake $(0.70 \mathrm{~g})$.

\section{References}

[1] S. K. Kunnath, N. Panahshahi, and A. M. Reinhorn, "Seismic response of RC buildings with inelastic floor diaphragms," Journal of Structural Engineering (United States), vol. 117, no. 4, pp. 1218-1237, 1991.

[2] S. H. Ju and M. C. Lin, "Comparison of building analyses assuming rigid or flexible floors," Journal of Structural Engineering, vol. 125, no. 1, pp. 25-31, 1999.
[3] V. K. Sadashiva, G. A. Macrae, B. L. Deam, and M. S. Spooner, "Quantifying the seismic response of structures with flexible diaphragms," Earthquake Engineering \& Structural Dynamics, vol. 41, no. 10, pp. 1365-1389, 2012.

[4] A. K. L. Damian, C. T. Bia, O. Gosa, H. Maniu, and C. S. Dico, "Diaphragm behaviour of the floor with prestressed beam and filler blocks," in Proceedings of the 12th World Conference on Earthquake Engineering (WCEE 12), Paper No. 0696, Auckland, New Zealand, February 2000. 
[5] E. R. Mario, S. Santiago, and R. Meli, "Seismic load tests on two-story waffle-flat-plate structure," Journal of Structural Engineering (United States), vol. 121, no. 9, pp. 1287-1293, 1995.

[6] A. Tena-Colunga, K. L. Chinchilla-Portillo, and G. Juárez-Luna, "Assessment of the diaphragm condition for floor systems used in urban buildings," Engineering Structures, vol. 93, pp. 70-84, 2015.

[7] M. A. Hadianfard and S. Sedaghat, "Investigation of joist floor diaphragm flexibility on inelastic behavior of steel braced structures," Scientia Iranica, vol. 20, no. 3, pp. 445-453, 2003.

[8] J. De-La-Colina, "In-plane floor flexibility effects on torsionally unbalanced systems," Earthquake Engineering \& Structural Dynamics, vol. 28, no. 12, pp. 1705-1715, 1999.

[9] O. A. López and E. Raven, "An Overall Evaluation of Irregular-Floor-Plan-Shaped Buildings Located in Seismic Areas," Earthquake Spectra, vol. 15, no. 1, pp. 105-120, 1999.

[10] P. Somers, D. Campi, W. Holmes, B. E. Kehoe et al., "Unreinforced masonary buildings," Earthquake Spectra, vol. 12, no. S1, pp. 195-217, 1996.

[11] R. Shepherd, W. T. Holmes, B. Lizundia et al., "Buildings," Earthquake Spectra, vol. 6, no. S1, pp. 127-149, 1990.

[12] H. S. Saffarini and M. M. Qudaimat, "In-plane floor deformations in RC structures," Journal of Structural Engineering (United States), vol. 118, no. 11, pp. 3089-3102, 1992.

[13] S.-K. Moon and D.-G. Lee, "Effects of inplane floor slab flexibility on the seismic behaviour of building structures," Engineering Structures, vol. 16, no. 2, pp. 129-144, 1994.

[14] H. J. Lee, M. A. Aschheim, and D. Kuchma, "Interstory drift estimates for low-rise flexible diaphragm structures," Engineering Structures, vol. 29, no. 7, pp. 1375-1397, 2007.

[15] R. B. Fleischman and K. T. Farrow, "Dynamic behavior of perimeter lateral-system structures with flexible diaphragms," Earthquake Engineering \& Structural Dynamics, vol. 30, no. 5, pp. 745-763, 2001.

[16] G. Magenes, A. Penna, I. E. Senaldi, M. Rota, and A. Galasco, "Shaking table test of a strengthened full-scale stone masonry building with flexible diaphragms," International Journal of Architectural Heritage, vol. 8, no. 3, pp. 349-375, 2014.

[17] I. Senaldi, G. Magenes, A. Penna, A. Galasco, and M. Rota, "The effect of stiffened floor and roof diaphragms on the experimental seismic response of a full-scale unreinforced stone masonry building," Journal of Earthquake Engineering, vol. 18, no. 3, pp. 407-443, 2014.

[18] S.-C. Kim and D. W. White, "Nonlinear analysis of a one-story low-rise masonry building with a flexible diaphragm subjected to seismic excitation," Engineering Structures, vol. 26, no. 14, pp. 2053-2067, 2004.

[19] Y. Nakamura, H. Derakhshan, G. Magenes, and M. C. Griffith, "Influence of Diaphragm Flexibility on Seismic Response of Unreinforced Masonry Buildings," Journal of Earthquake Engineering, vol. 21, no. 6, pp. 935-960, 2017.

[20] T. Paulay, "Seismic response of structural walls: Recent developments," Canadian Journal of Civil Engineering, vol. 28, no. 6, pp. 922-937, 2001.

[21] M. J. N. Priestley and M. J. Kowalsky, "Aspects of drift and ductility capacity of rectangular cantilever structural walls," Bulletin of the New Zealand National Society forEarthquake Engineering and Structural Dynamics, vol. 31, no. 2, pp. 73-85, 1998.

[22] T. Paulay, "Seismic torsional effects on ductile structural wall systems," Journal of Earthquake Engineering, vol. 1, no. 4, pp. 721-745, 1997.
[23] W. K. Tso and R. S. H. Smith, "Re-evaluation of seismic torsional provisions," Earthquake Engineering \& Structural Dynamics, vol. 28, no. 7-8, pp. 899-917, 1999.

[24] T. Paulay, "Some design principles relevant to torsional phenomena in ductile buildings," Journal of Earthquake Engineering, vol. 5, no. 3, pp. 273-308, 2001.

[25] W. K. Tso and B. Myslimaj, "Effect of strength distribution on the inelastic torsional response of asymmetric structural systems," in Proceedings of the 12th European Conference on Earthquake Engineering, Paper No. 081, London, UK, September 2002.

[26] A. Aziminejad and A. S. Moghadam, "Fragility-based performance evaluation of asymmetric single-story buildings in near field and far field earthquakes," Journal of Earthquake Engineering, vol. 14, no. 6, pp. 789-816, 2010.

[27] Iranian national building code, Part 6. Design Loads for Buildings, Building and Housing Research Center, Tehran, Iran, 2013.

[28] Standard No. 2800, Iranian Code of Practice for Seismic Resistant Design of Buildings, Building and Housing Research Center, Tehran, Iran, 2014.

[29] A. Rutenburg, "EAEE task group 8: Behaviour of irregular and complex structures: progress since 1998," in Proceedings of the 12th European Conference on Earthquake Engineering, Paper No. 832, London, UK, September 2002.

[30] B. Myslimaj and W. K. Tso, "A strength distribution criterion for minimizing torsional response of asymmetric wall-type systems," Earthquake Engineering \& Structural Dynamics, vol. 31, no. 1, pp. 99-120, 2002.

[31] B. Myslimaj and W. K. Tso, "A design-oriented approach to strength distribution in single-story asymmetric systems with elements having strength-dependent stiffness," Earthquake Spectra, vol. 21, no. 1, pp. 197-212, 2005.

[32] M. De Stefano, G. Faella, and R. Ramasco, "Inelastic response and design criteria of plan-wise asymmetric systems," Earthquake Engineering \& Structural Dynamics, vol. 22, no. 3, pp. 245-259, 1993.

[33] ASCE/SEI 7-10, Minimum Design Loads for Buildings and Other Structures, American Society of Civil Engineers, Reston, Va, US, 2010.

[34] M. Silvia, M. Frank, and H. Michael, Open System for Earthquake Engineering Simulation User Manual, Pacific Earthquake Engineering Research Center, University of California, Berkeley, Calif, USA, 2005.

[35] S. Mazzoni, F. McKenna, and G. L. Fenves, OpenSees Command Language Manual, Pacific Earthquake Engineering Center, University of California, Berkeley, Calif, USA, 2005.

[36] M. J. N. Priestley, G. M. Calvi, and M. J. Kowalsky, DisplacementBased Seismic Design of Structures, IUSS Press, Pavia, Italy, 2007.

[37] E. M. Rathje, C. Dawson, J. E. Padgett et al., "DesignSafe: new cyberinfrastructure for natural hazards engineering," Natural Hazards Review, vol. 18, no. 3, 2017. 


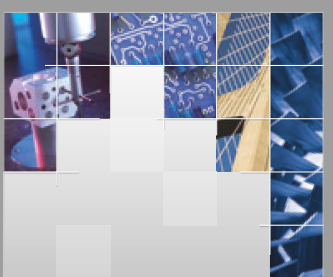

\section{Enfincering}
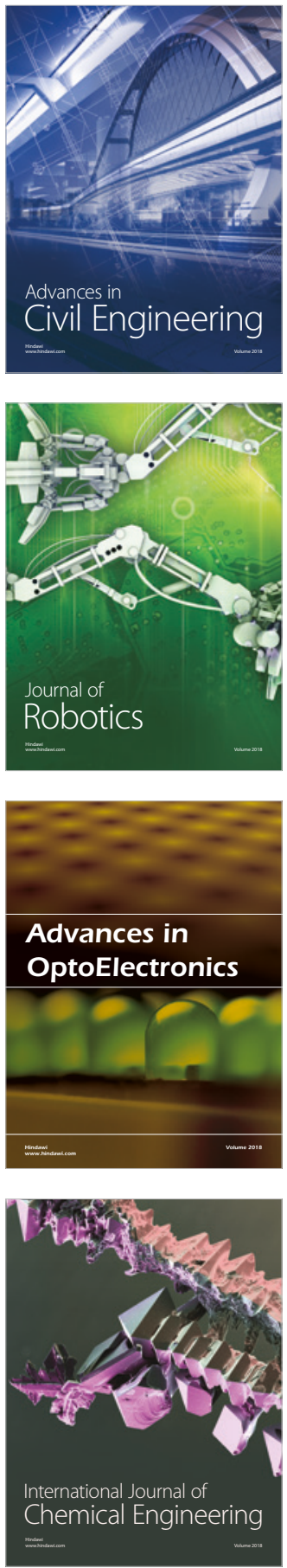

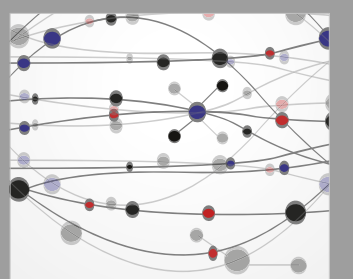

\section{Rotating \\ Machinery}

The Scientific World Journal

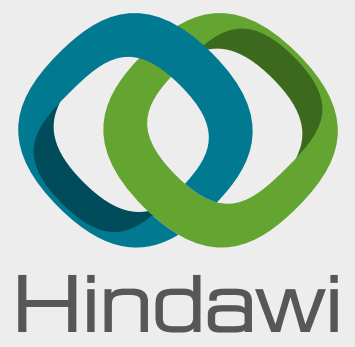

Submit your manuscripts at

www.hindawi.com
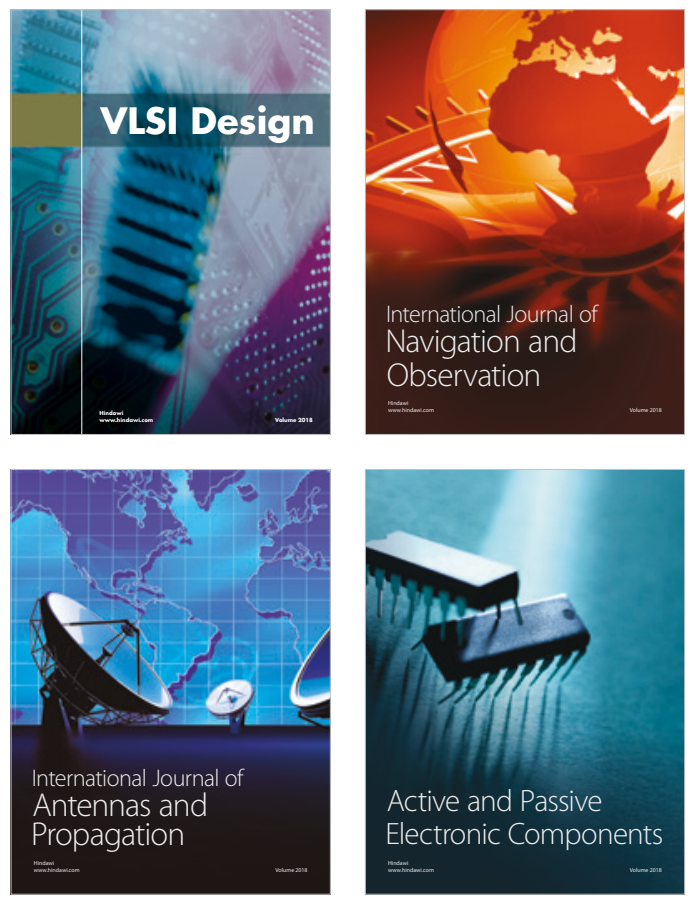
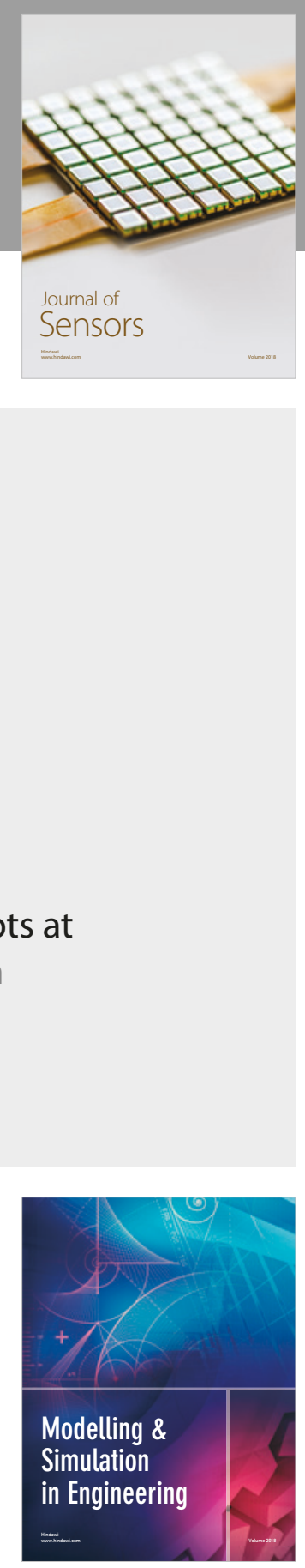

\section{Advances \\ Multimedia}
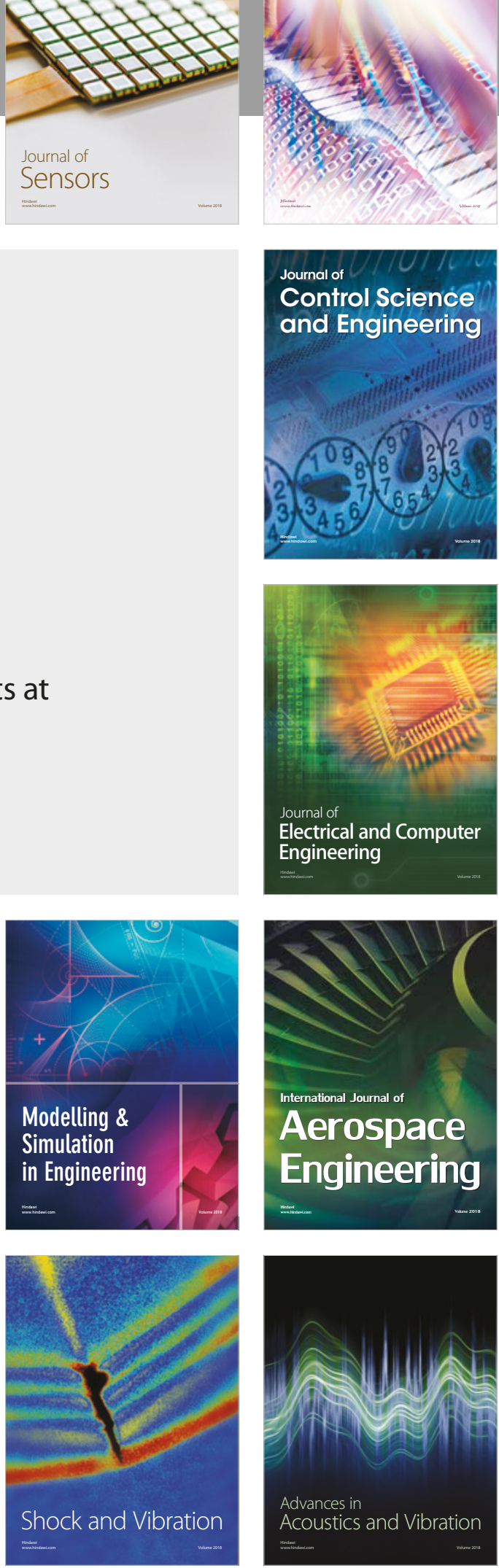